\author{
Supporting Information
}

\title{
Highly Efficient Hydrogen Generation from a Formic Acid/Triethanolamine System Using a Pd-Based Catalyst and Correlation for Apparent Activation Energy Estimation
}

Liangyu Zou, Qiaoyu Zhang, Yangqiang Huang*, Xiao Luo, Zhiwu Liang*

Joint International Center for $\mathrm{CO}_{2}$ Capture and Storage (iCCS), Provincial Hunan Key Laboratory for Cost-effective Utilization of Fossil Fuel Aimed at Reducing $\mathrm{CO}_{2}$

Emissions, College of Chemistry and Chemical Engineering, Hunan University, Changsha, Hunan 410082, P.R. China

*CORRESPONDING AUTHOR:

E-mail addresses: yqhuang@hnu.edu.cn (Y. Huang), zwliang@hnu.edu.cn (Z. Liang) 
Tel.: +86-13618481627; Fax: +86-731-88573033. 


\section{S1. Materials}

The information of the amines for experimental study in this work was listed in

Table S1. 2-(Ethylamino)ethanol (MEEA, Aladdin Reagent, 99\%), formic acid (FA, Sinopharm Chemical Reagent Co., Ltd, 98\%), industrial grade sepiolite (IG-SEP, Hunan Yuanyuan Sepiolite Co., Ltd, 99.5\%), hydrochloric acid (HCl, Sinopharm Chemical Reagent Co., Ltd, 36\% 37\%), palladium chloride $\left(\mathrm{PdCl}_{2}\right.$, Sinopharm Chemical Reagent Co., Ltd, $\geqslant 59 \%$ ), sodium chloride ( $\mathrm{NaCl}$, Sinopharm Chemical Reagent Co., Ltd, $\geqslant 99.8 \%)$, sodium borohydride $\left(\mathrm{NaBH}_{4}\right.$, Sinopharm Chemical Reagent Co., Ltd, 98\%), sodium carbonate $\left(\mathrm{Na}_{2} \mathrm{CO}_{3}\right.$, Macklin Biochemical Technology Co., Ltd, $\geqslant 99.5 \%)$, sodium bicarbonate $\left(\mathrm{NaHCO}_{3}\right.$, Macklin Biochemical Technology Co., Ltd, $\geqslant 99.5 \%$ ), aminopropyl triethoxysilane (APTS, Aladdin Reagent, 99\%), Silicon dioxide ( $\mathrm{SiO}_{2}$, Aladdin Reagent, 99.99\%), Magnesium oxide (MgO, Aladdin Reagent, $\geqslant 98 \%$ ), Melamine (Macklin Biochemical Technology, 99\%), Cabot Vulcan XC-72 (XC-72, Macklin Biochemical Technology), $\mathrm{pH}$ meter with accuracy of \pm 0.01 (model E-201-C, INESA Scientific Instruments, China), viscometer with accuracy of $\pm 0.25 \%$ ( model:Lovis $2000 \mathrm{M} / \mathrm{ME}$, Anton Paar). The deionized water was produced by a reverse osmosis ultra-pure water equipment (Model TS-RO-10L/H, $\leqslant 0.1 \mu \mathrm{s} / \mathrm{cm}$, Taoshi Water Equipment Engineering Co. Ltd.).

\section{S2. Characterizations}


The Pd content of prepared catalysts sample was dissolved in a solution of $\mathrm{HNO}_{3} / \mathrm{HCl}(1 / 3, \mathrm{v} / \mathrm{v})$ and was accurately determined by ICP-OES (PerkinElmer 8300). The X-ray photoelectron spectrometer (XPS) tests were taken by the Thermo Fisher Scientific K-Alpha + spectrometer. The transmission electron microscopy (TEM) images and elemental mapping images were taken by a JEOL $2100 \mathrm{~F}$ of transmission electron microscopes, the sample support uesed traditional micro grid copper mesh. The XRD patterns of samples were collected by using an Ultima IV multipurpose X-ray diffraction system with $\mathrm{Cu}-\mathrm{K} \alpha$ radiation $(40 \mathrm{kV}, 55 \mathrm{~mA})$. The IR spectroscopy of samples were carried out in the Fourier Transform Infrared spectrometer (TENSOR27). The Ultraviolet spectrophotometer (U-3010) was used in determine log $\mathrm{P}$ of amines. The gases samples collected from gas composition analysis test tests were analyzed by gas chromatography (SP-6890). The $\mathrm{N}_{2}$ adsorption-desorption isotherms of samples were performed by an automated gas sorption analyzer (TriStar II 3 flex) after the samples were degassed at $373 \mathrm{~K}$ for $6 \mathrm{~h}$.

\section{S3. Preparation of Sepiolite Carrier and Precursor Liquid}

Prior to use, the sepiolite clay was first dried in an oven at $383 \mathrm{~K}$ for 6 hours at least to remove physically adsorbed $\mathrm{H}_{2} \mathrm{O}$. To enhance its hydrophilicity, the dried sepiolite needs premodified by hydrochloric acid. $10 \mathrm{~g}$ of sepiolite was added into 100 $\mathrm{mL}$ of $2 \mathrm{M}$ (abbr. of $\mathrm{mol} / \mathrm{L}$ ) $\mathrm{HCl}$ solution, and the hybrid solution was stirred for 15 hours under ambient conditions. Then the extracted filtration process was used on the mixture. The filtered cake was washed by saturated $\mathrm{NaHCO}_{3}$ solution and distilled 
water, for the purpose of removing chloridion. Then, the washed sample was dried in an oven at $373 \mathrm{~K}$ for 12 hours and crushed to powders. The obtained sepiolite are denoted as "SEP-H".

The next step is surface modification procedure. A total of $2 \mathrm{~g}$ acid-modified sepiolite was added into a three-necked flask with $100 \mathrm{~mL}$ anhydrous ethanol, stirring fully for 20 minutes at room temperature (about $298 \mathrm{~K}$ ). Then the $0.3 \mathrm{~mL}$ deionized water was injected into the mixture and stirred continuously for another 30 minutes. The temperature of the solution is then raised to $343 \mathrm{~K}$ with a heating rate of $4 \mathrm{~K} / \mathrm{min}$. When the temperature is constant at $343 \mathrm{~K}, 0.9 \mathrm{~g}$ of aminopropyl triethoxysilane (APTS) is added, and the whole solution is stirred for another 18 hours at a rate of 700 rpm. Then, the mixture was filtered and washed with anhydrous ethanol repeatedly. After the drying process under $363 \mathrm{~K}$ for 12 hours, the dried sample was powdered and sieved to 200 mesh particle size. In the end, the modified sepiolite was obtained and used as catalyst supports. The obtained amine-functionalized carriers are denoted as "NH $2-\mathrm{SEP}-\mathrm{H}$ ". Similarly, the catalysts using $\mathrm{SiO}_{2}, \mathrm{MgO}, \mathrm{XC}-72$ and $\mathrm{g}-\mathrm{C}_{3} \mathrm{~N}_{4}$ as support by same preparation procedure were named as $\mathrm{NH}_{2}-\mathrm{SiO}_{2}-\mathrm{H}, \mathrm{NH}_{2}-\mathrm{MgO}-\mathrm{H}$ and $\mathrm{NH}_{2}-\mathrm{gC}_{3} \mathrm{~N}_{4}-\mathrm{H}$, respectively.

Synthesis of $0.05 \mathrm{M} \mathrm{Na}_{2} \mathrm{PdCl}_{4}$ was achieved by mixing $0.2 \mathrm{M} \mathrm{NaCl}$ and $0.1 \mathrm{M}$ $\mathrm{PdCl}_{2}$ with a $1: 1$ molar ratio. The specific operation method is that $0.88 \mathrm{~g} \mathrm{PdCl}_{2}$ was added to a $10 \mathrm{~mL} 0.1 \mathrm{M} \mathrm{NaCl}$ solution.

\section{S4. Calculation of Dissociation Constant $\left(\mathrm{pK}_{\mathrm{a}}\right)$ and Viscosity $(\mu)$}


The $\mathrm{pH}$ value of different amines at $303 \mathrm{~K}$ was measured by $\mathrm{pH}$ meter, and the method for the $\mathrm{pK}_{\mathrm{a}}$ determination is obtained by Liu's work ${ }^{1}$. Viscosity $(\mu)$ values of aqueous hybrid FA/amine solution were obtained using a viscometer with accuracy of $0.02 \mathrm{~K}$ with temperature controlled by a water-bath thermostat. The method of determination for oil-water partition coefficient $(\log \mathrm{P})$ values of amines were obtained from Li's and Qiao's work ${ }^{2,3}$. The values are listed in Table 1.

\section{S5. Characterization Results}

Characterization analyses were conducted to investigate the chemical states, structure and morphology of the specimens includes the Pd/ $\mathrm{NH}_{2}-\mathrm{SEP}-\mathrm{H}, \mathrm{Pd} / \mathrm{SEP}-\mathrm{H}$, SEP-H, and SEP-IG. As shown in Figure S1, the N peak at $399.3 \mathrm{eV}$ are observed for the $\mathrm{Pd} / \mathrm{NH}_{2}-\mathrm{SEP}-\mathrm{H}$ catalyst, whereas such $\mathrm{N}$ distinct peaks do not exist in $\mathrm{Pd} / \mathrm{SEP}-\mathrm{H}$, further suggesting that the amino groups from APTS have been successfully decorated into $\mathrm{Pd} / \mathrm{NH}_{2}-\mathrm{SEP}-\mathrm{H}$ catalyst ${ }^{4}$. As shown in Figure 4 , it can be seen that $\mathrm{Pd}$ in both $\mathrm{Pd} / \mathrm{SEP}-\mathrm{H}$ and $\mathrm{Pd} / \mathrm{NH}_{2}-\mathrm{SEP}-\mathrm{H}$ are mostly in coexistence of $\mathrm{Pd}^{0}$ and $\mathrm{Pd}^{2+}$ species. Based on the above XPS analysis, it can be deduced that the addition of $\mathrm{N}$ to $\mathrm{Pd}$ can adjust the electron structure of Pd through the electron synergetic effect, while the support of $\mathrm{NH}_{2}-\mathrm{SEP}-\mathrm{H}$, can also modify the electron structure of the metal NPs through the strong SMSI (Strong Metal-Support Interactions) effect ${ }^{5}$.

Figure S2a shows the transmission electron microscopy (TEM) images of $\mathrm{Pd} / \mathrm{NH}_{2}-\mathrm{SEP}-\mathrm{H}$ catalyst with different magnifications. Obviously, ultrafine $\mathrm{Pd}$ nanoparticles are highly dispersed on the grafted-sepiolite surface with a small 
particle size $(2 \pm 0.5 \mathrm{~nm})$ (Figure $\mathrm{S} 2 \mathrm{~b})$. Apparently, the $\mathrm{Pd}$ nanoparticles are successfully immobilized on grafted-sepiolite. The elemental mappings show that the metal and non-metal elements were homogeneously distributed in the randomly selected area (Figure 5a-h). Elemental mapping images display the uniform distribution of $\mathrm{N}$ and $\mathrm{Pd}$ on the grafted sepiolite, which indicated the successfully formation of homogeneous Pd alloy NPs on $\mathrm{NH}_{2}-\mathrm{SEP}-\mathrm{H}$ carriers ${ }^{6}$. Figure 2 shows the most evident peak corresponding to $\mathrm{Si}-\mathrm{O}$ and $\mathrm{O}-\mathrm{Si}-\mathrm{O}$ stretching vibration (1034 and $467 \mathrm{~cm}^{-1}$, respectively) $)^{7,8}$, namely, sepiolites constitute of the tetrahedral silica sheets. From another aspect, it also indicates that layers of Si-O structure were not damaged greatly in the process of catalyst making.

The FTIR spectra of SEP-IG shows a broad peak at $3000 \sim 3700 \mathrm{~cm}^{-1}$, which is caused by the vibration of $-\mathrm{OH}$ existing in the framework of $\mathrm{SEP}^{9}$, such as $\mathrm{Si}-\mathrm{OH}$ and Fe-OH species. For SEP, The band at $3675 \mathrm{~cm}^{-1}$, caused by the stretching vibration of $\mathrm{Fe}-\mathrm{OH}$ disappeared after the acid-treatment due to the removal of abundant $\mathrm{Fe}$ element ${ }^{10}$. It can be seen in Figure 2 that the three specimens have no evident changes in those patterns, whether after functionalization of the amino group or the impregnation of the Pd NPs, which proves the stable structure during the preparation process of the specimens.

The Pd NPs is formed in the structure low crystallinity of uniformly dispersion, and this can be confirmed by the XRD pattern of $\mathrm{Pd} / \mathrm{NH}_{2}-\mathrm{SEP}-\mathrm{H}$ where characteristic diffraction peaks of Pd (JCPDS: $46-1043)$ at $39.8^{\circ}(111)$ and $45.9^{\circ}(200)$ are hardly observable (Figure S3), which may be attributed to the formation of very small and 
uniformly dispersed Pd NPs on sepiolite. The diffraction peaks at $2 \theta$ values of 26.7 and 36.3 match the (101) crystal diffraction of quartz (JCPDS: 46-1045), indicating the similar composite structure between the sepiolite and quartz. It can be seen that the vanish of characteristic peaks at $2 \theta=7.4^{\circ}$ of $\mathrm{SEP}^{11}$, corresponding to the (110) crystal plane of sepiolite after the acid treatment process, which is attributed to the collapse of the sepiolite internal pore structure ${ }^{12}$.

Also, the $\mathrm{N}_{2}$ adsorption/desorption results show that the surface areas of $\mathrm{Pd} / \mathrm{NH}_{2}-\mathrm{SEP}-\mathrm{H}, \mathrm{Pd} / \mathrm{SEP}-\mathrm{H}, \mathrm{SEP}-\mathrm{H}$ all decrease compared with IG-SEP, which is $81.36,84.85,118.14$ and $149.72 \mathrm{~m}^{2} / \mathrm{g}$, respectively (Table S2). The decrement from 149.72 to $118.14 \mathrm{~m}^{2} / \mathrm{g}$ could be attributed to the partial internal channel of SEP-IG collapsing during the removal of impurities after the acid-treatment process, then the deposition of metal NPs into the sepiolite frameworks further occupies the space of internal channel ${ }^{13}$. The pore volume of $\mathrm{Pd} / \mathrm{NH}_{2}-\mathrm{SEP}-\mathrm{H}$ and $\mathrm{Pd} / \mathrm{SEP}-\mathrm{H}$ is 0.438 and $0.448 \mathrm{~cm}^{3} / \mathrm{g}$, respectively. This is because that the incorporation of $-\mathrm{NH}_{2}$ groups could functionalize on the inner pores of sepolite. Figure S4 presents the H3-type hysteresis loop and typical type-IV adsorption isotherm for all samples, which manifests that the crack-type mesoporous structure in carriers of sepiolite.

\section{S6. Verification of Elimination for External Diffusion Effects}

The catalyst was tested for FA dehydrogenation of each FA/amine hybrid reaction is maintained constant with $750 \mathrm{rpm}$. The free of external diffusion limitation has been confirmed by Figure S21, S22, where the reaction rate is not influenced by the 
stirring speed. The observed pheomenon suggests that the reaction hybrid system (like TEOA, MDEA) is not limited by external diffusion of reactants in establishment of correlated functions. 


\section{References}

(1) Liu, S.; Gao, H.; He, C.; Liang, Z. Experimental evaluation of highly efficient primary and secondary amines with lower energy by a novel method for post-combustion $\mathrm{CO}_{2}$ capture. Appl. Energ. 2019, 233-234, 443-452.

(2) Qiao, Y., 'Determination and estimation of n-octanol/water distribution coefficient of some aromatic hydrocarbon derivatives' (Tianjin University, 2007).

(3) li, J.; Huang, Q.; Liao, 1. Structural characterization of aliphatic amine and prediction of n-octanol/water partition coefficient. J. Com. Appl. Chem. 2017, 34, 560-562.

(4) Buchwalter, L.; Greenblatt, J. An XPS study of the locus of failure between PMDA-ODA polyimide and $\mathrm{SiO}_{2}$ surface. J. Adhesion 1986, 19, 257-265.

(5) Yadav, M.; Akita, T.; Tsumori, N.; Xu, Q. Strong metal-molecular support interaction (SMMSI): amine-functionalized gold nanoparticles encapsulated in silica nanospheres highly active for catalytic decomposition of formic acid. J. Mater. Chem. 2012, 22, 12582-12586.

(6) Cheng, J.; Gu, X.; Liu, P.; Zhang, H.; Ma, L.; Su, H. Achieving efficient room-temperature catalytic $\mathrm{H}_{2}$ evolution from formic acid through atomically controlling the chemical environment of bimetallic nanoparticles immobilized by isoreticular amine-functionalized metal-organic frameworks. Appl. Catal. B-Environ. 2017, 218, 460-469.

(7) Liu, H.; Chen, W. Magnetic mesoporous imprinted adsorbent based on $\mathrm{Fe}_{3} \mathrm{O}_{4}$-modified sepiolite for organic micropollutant removal from aqueous solution. $R S C A d v \mathbf{2 0 1 5}, 5,27034-27042$.

(8) Liu, S.; Xue, C.; Yang, H.; Huang, X.; Zou, Y.; Ding, Y.; Li, L.; Ren, X. Intercalated hybrid of kaolinite with $\mathrm{KH}_{2} \mathrm{PO}_{4}$ showing high ionic conductivity $\left(\sim 10^{-4} \mathrm{~S} \mathrm{~cm}^{-1}\right)$ at room temperature. Solid State Sci. 2017, 74, 95-100.

(9) Omran, A. V.; Pulpytel, J.; Arefi-Khonsari, F. Cell-adherent $\mathrm{SiO}_{\mathrm{x}}$ coatings developed by an atmospheric transporting discharge. Plasma Med. 2018, 8.

(10) Iwasaki, M.; Shinjoh, H. NO evolution reaction with $\mathrm{NO}_{2}$ adsorption over Fe/ZSM-5: In situ FT-IR observation and relationships with Fe sites. J. Catal. 2010, 273, 29-38.

(11) Zhou, F.; Yan, C.; Wang, H.; Zhou, S.; Komarneni, S. Fabrication and characterization of $\mathrm{TiO}_{2} /$ Sepiolite nanocomposites doped with rare earth ions. Mater. Lett. 2018, 228, 100-103. 
(12) Zhang, Q.; Zhu, Z.; Zhang, X.; Li, P.; Huang, Y.; Luo, X.; Liang, Z. Amine-functionalized sepiolite: Toward highly efficient palladium nanocatalyst for dehydrogenation of additive-free formic acid. Int. J. Hydrogen Energ. 2019, 44, 16707-16717.

(13) Puthiaraj, P.; Ahn, W.-S. Highly active palladium nanoparticles immobilized on NH2-MIL-125 as efficient and recyclable catalysts for Suzuki-Miyaura cross coupling reaction. Catal. Commun. 2015, 65, 91-95.

(14) Wang, Z.; Yan, J.; Wang, H.; Ping, Y.; Jiang, Q. Pd/C synthesized with citric acid: an efficient catalyst for hydrogen generation from formic acid/sodium formate. Sci. Rep. 2012, 2, 1-6.

(15) Martis, M.; Mori, K.; Fujiwara, K.; Ahn, W.-S.; Yamashita, H. Amine-functionalized MIL-125 with imbedded palladium nanoparticles as an efficient catalyst for dehydrogenation of formic acid at ambient temperature. J. Phys. Chem. C 2013, 117, 22805-22810.

(16) Jiang, K.; Xu, K.; Zou, S.; Cai, W. B-doped Pd catalyst: boosting room-temperature hydrogen production from formic acid-formate solutions. J. Am. Chem. Soc. 2014, 136, 4861-4864.

(17) Yao, F.; Li, X.; Wan, C.; Xu, L.; An, Y.; Ye, M.; Lei, Z. Highly efficient hydrogen release from formic acid using a graphitic carbon nitride-supported AgPd nanoparticle catalyst. Appl. Surf. Sci. 2017, 426, 605-611.

(18) Dai, H.; Xia, B.; Lan, W.; Cheng, D.; Su, J.; Wei, L.; Cheng, G. Synergistic catalysis of AgPd@ZIF-8 on dehydrogenation of formic acid. Appl. Catal. B-Environ. 2015, 165, 57-62.

(19) Zhu, Q.; Tsumori, N.; Xu, Q. Sodium hydroxide-assisted growth of uniform Pd nanoparticles on nanoporous carbon MSC-30 for efficient and complete dehydrogenation of formic acid under ambient conditions. Chem. Sci. 2014, 5, 195-199.

(20) Wu, S.; Yang, F.; Sun, P.; Chen, T. Au-Pd alloy catalyst with high performance for hydrogen generation from formic acid-formate solution at nearly $0{ }^{\circ} \mathrm{C} . R S C A d v . \mathbf{2 0 1 4}, 4,44500-44503$.

(21) Zhang, S.; Jiang, B.; Jiang, K.; Cai, W. Surfactant-free synthesis of carbon supported palladium nanoparticles and size dependent hydrogen production from formic acid-formate solution. ACS Appl. Mater. Inter. 2017, 9, 24678-24687.

(22) Zhou, J.; Zhang, J.; Dai, X. H.; Wang, X.; Zhang, S. Formic acid-ammonium formate mixture: A new system with extremely high dehydrogenation activity and capacity. Int. J. Hydrogen Energ. 2016, 41, 22059-22066.

(23) Bi, Q.; Lin, J.; Liu, Y.; Huang, F.; Cao, Y. Promoted hydrogen generation from formic acid with 
amines using $\mathrm{Au} / \mathrm{ZrO}_{2}$ catalyst. Int. J. Hydrogen Energ. 2016, 41, 21193-21202. 
Table S1. Comparison of Studied Amines as Additives for Formic Acid Dehydrogenation

Name (Abbr)

a. Aladdin Reagent, Aladdin Industrial Corporation, Shanghai, China.

b. Alfa Aesar Reagent, Alfa Aesar (China) Chemical Co., Ltd.

c. Macklin Reagent, Macklin (China) Biochemical Technology Co., Ltd. 
Table S2. Textural properties of the prepared samples

\begin{tabular}{|c|c|c|c|}
\hline \multirow{3}{*}{ Sample } & BET surface area & Pore volume & Average pore diameter \\
\hline & \multirow[b]{2}{*}{$\left(\mathrm{m}^{2} / \mathrm{g}\right)$} & \multirow[b]{2}{*}{$\left(\mathrm{cm}^{3} / \mathrm{g}\right)$} & \multirow[b]{2}{*}{$(\mathrm{nm})$} \\
\hline & & & \\
\hline SEP-IG & 149.72 & 0.459 & 12.27 \\
\hline SEP-H & 118.14 & 0.504 & 17.07 \\
\hline $\mathrm{Pd} / \mathrm{SEP}-\mathrm{H}$ & 84.85 & 0.448 & 21.28 \\
\hline $\mathrm{Pd} / \mathrm{NH}_{2}-\mathrm{SEP}-\mathrm{H}$ & 81.36, & 0.438 & 21.55 \\
\hline
\end{tabular}

Table S3. Catalytic activity of various catalysts in dehydrogenation of FA/additive system

\begin{tabular}{|c|c|c|c|c|c|c|}
\hline Catalyst & $\begin{array}{l}\text { FA/additive } \\
(\mathrm{mmol} / \mathrm{mmol})\end{array}$ & Additive & $\begin{array}{c}\text { Temperature } \\
(\mathrm{K})\end{array}$ & $\begin{array}{c}\text { Initial } \\
\text { TOF } \\
\left(\mathrm{h}^{-1}\right)\end{array}$ & $\begin{array}{c}\text { Average } \\
\text { particle } \\
\text { size }(\mathrm{nm})\end{array}$ & Reference \\
\hline $\mathrm{Pd} / \mathrm{NH}_{2}-\mathrm{SEP}-\mathrm{H}$ & $5.5 / 0.5$ & TEOA & 303 & 1687 & 2.0 & This work \\
\hline $\begin{array}{c}\text { Citric acid } \\
\text { modified } \mathrm{Pd} / \mathrm{C}\end{array}$ & $5.3 / 4.2$ & $\mathrm{SF}$ & 298 & 64 & 2.8 & 14 \\
\hline $\mathrm{Pd}-\mathrm{NH}_{2} / \mathrm{MIL}-125$ & $9.8 / 7.9$ & SF & 305 & 214 & 3.1 & 15 \\
\hline $\mathrm{Pd} / \mathrm{C} \mathrm{NaBH}_{4}$ & $11 / 8$ & SF & 303 & $304^{\mathrm{a}}$ & 2.2 & 16 \\
\hline $\mathrm{AgPd} / \mathrm{g}-\mathrm{C}_{3} \mathrm{~N}_{4}$ & $3 / 1$ & SF & 323 & 480 & 3.0 & 17 \\
\hline $\mathrm{Ag}_{18} \mathrm{Pd} 82 @ \mathrm{ZIF}-8$ & $3 / 1$ & $\mathrm{SF}$ & 353 & $580^{\mathrm{a}}$ & 1.6 & 18 \\
\hline $\begin{array}{c}\mathrm{NaOH} \text { assisted- } \\
\mathrm{Pd} / \mathrm{MSC}-30\end{array}$ & $9 / 9$ & SF & 298 & 750 & 2.3 & 19 \\
\hline $\mathrm{Au}_{6} \mathrm{Pd}_{4} / \mathrm{C}$ & $11 / 40$ & SF & 298 & $1075^{\mathrm{a}}$ & 2.0 & 20 \\
\hline $\begin{array}{c}\text { Surfactant-Rree } \\
\mathrm{Pd} / \mathrm{C}\end{array}$ & $5.5 / 4$ & $\mathrm{SF}$ & 303 & 1272 & 2.0 & 21 \\
\hline $\mathrm{Pd} / \mathrm{C}$ & $10 / 40$ & $\mathrm{AF}^{\mathrm{b}}$ & 303 & $1069^{a}$ & 2.46 & 22 \\
\hline $\mathrm{Au} / \mathrm{ZrO}_{2}$ & $53 / 21.2$ & DMEA & 333 & 1166 & 1.8 & 23 \\
\hline
\end{tabular}

a. Denotes the intial TOF values were calculated according to the amount of released $\mathrm{CO}_{2}+\mathrm{H}_{2}$ gases (The remaining initial TOF values were calculated according to the amount of released $\mathrm{H}_{2}$ gas)

b. AF is the abbreviation of ammonium formate. 


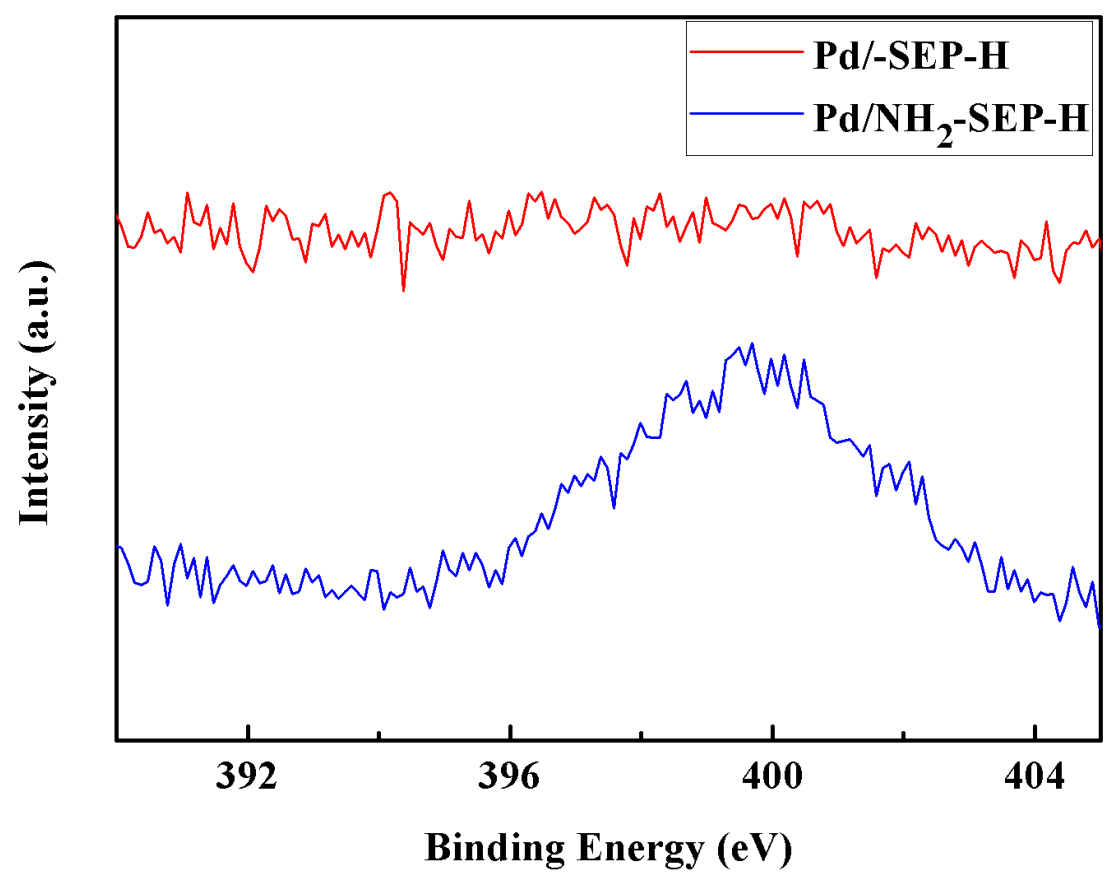

Figure S1. XPS patterns of the $\mathrm{N}$ 1s for the $\mathrm{Pd} / \mathrm{NH}_{2}-\mathrm{SEP}-\mathrm{H}$ and $\mathrm{Pd} / \mathrm{SEP}-\mathrm{H}$

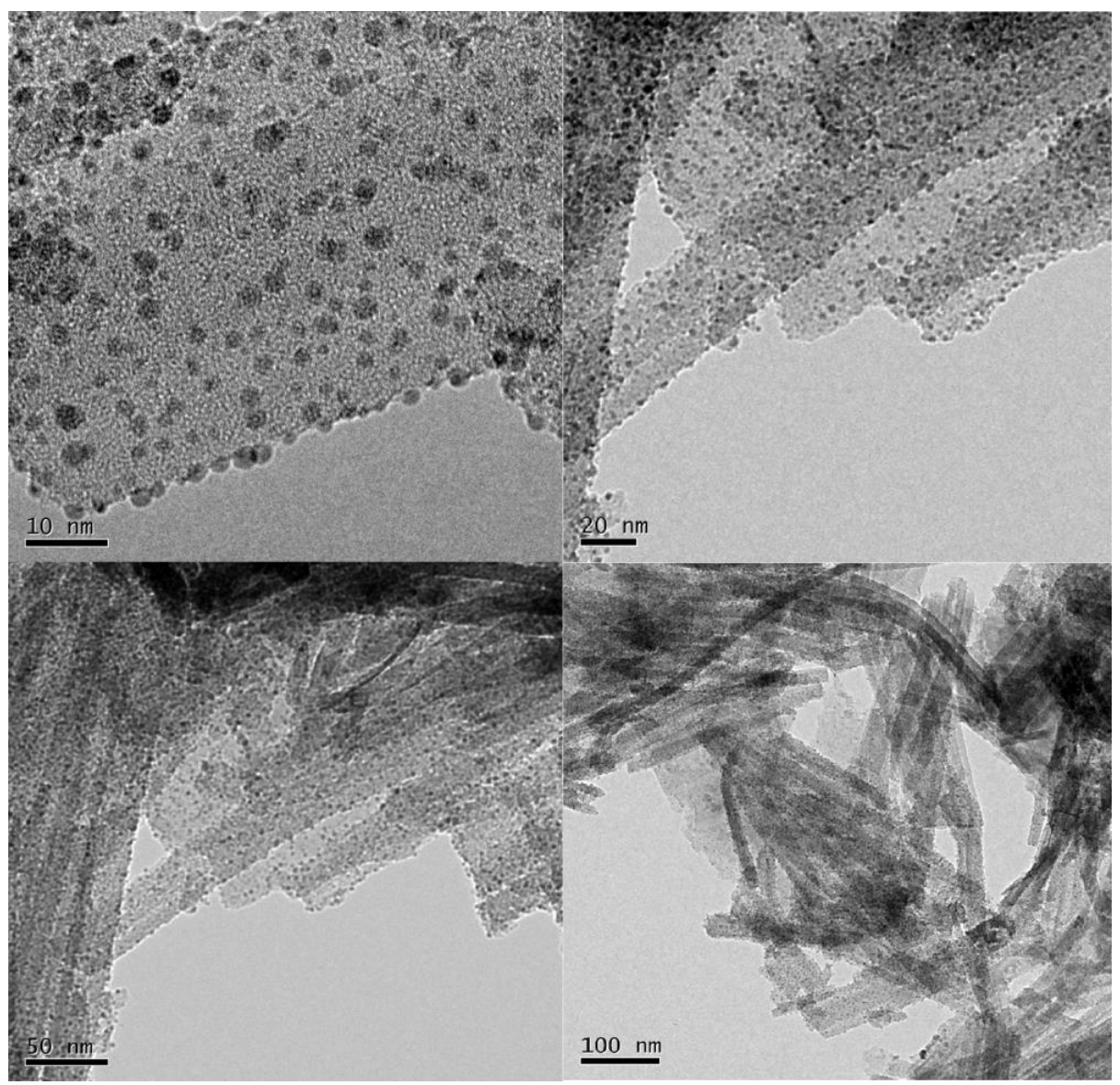

Figure S2a. TEM images of $\mathrm{Pd} / \mathrm{NH}_{2}-\mathrm{SEP}-\mathrm{H}$ catalyst with different magnifications. 


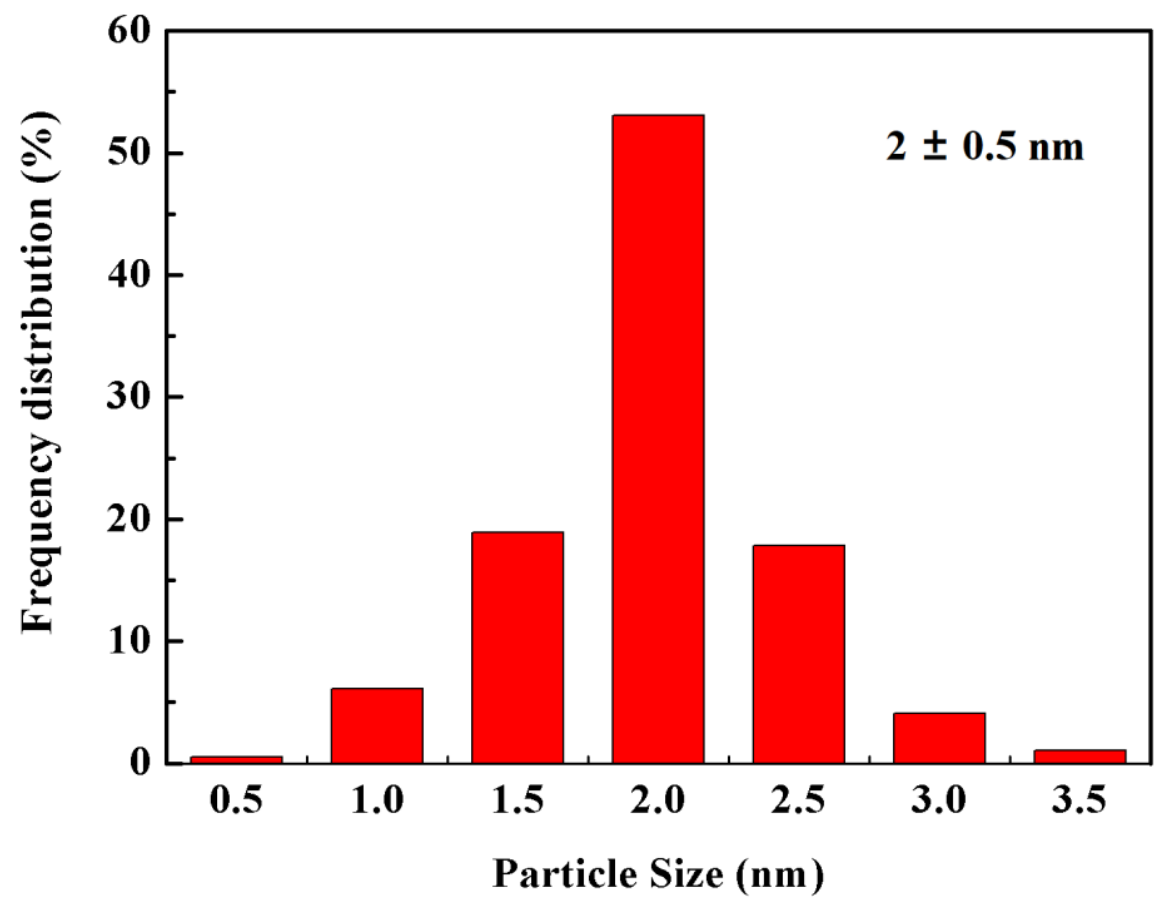

Figure S2b. Distribution of $\mathrm{Pd} / \mathrm{NH}_{2}-\mathrm{SEP}-\mathrm{H}$ catalyst nanoparticle size.

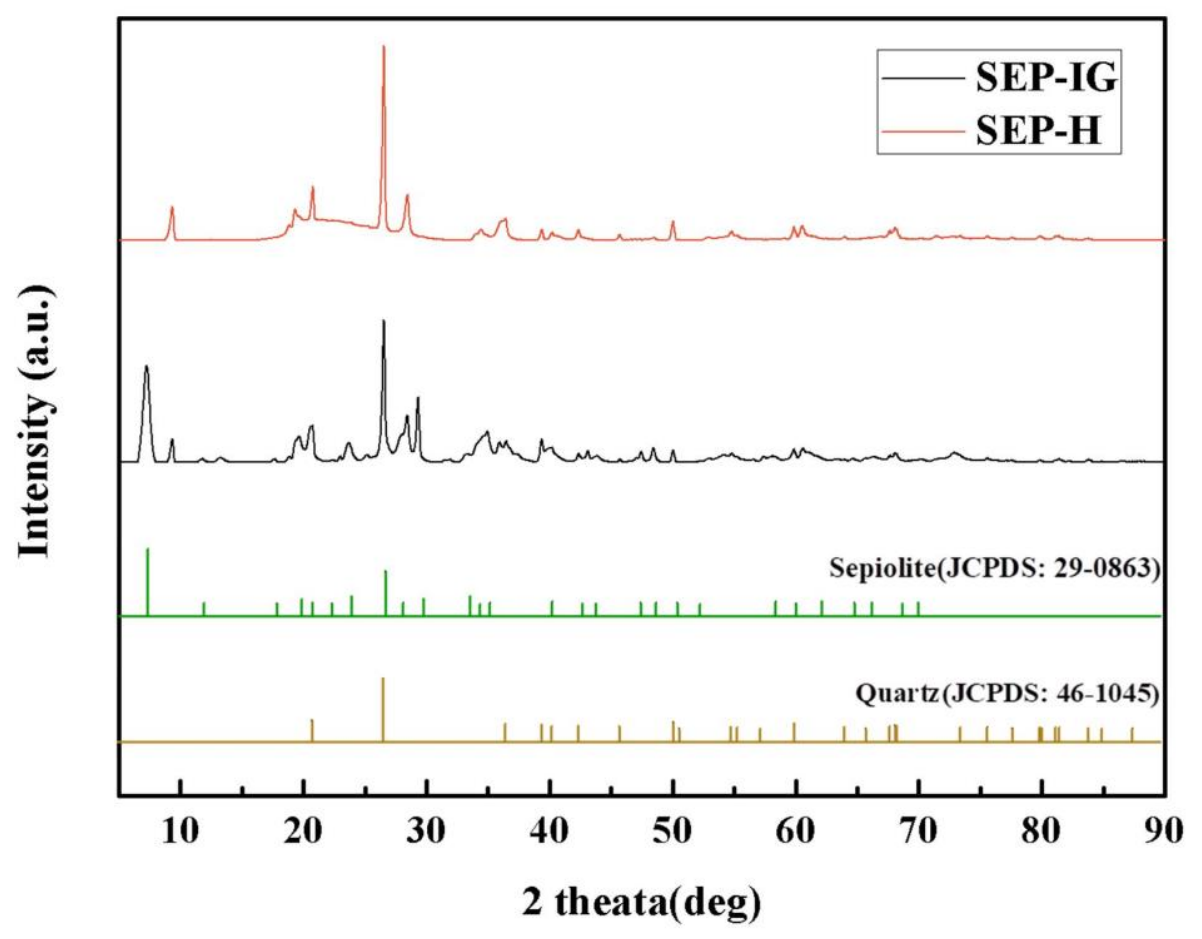

Figure S3a. XRD spectra of SEP-H and SEP-IG. 


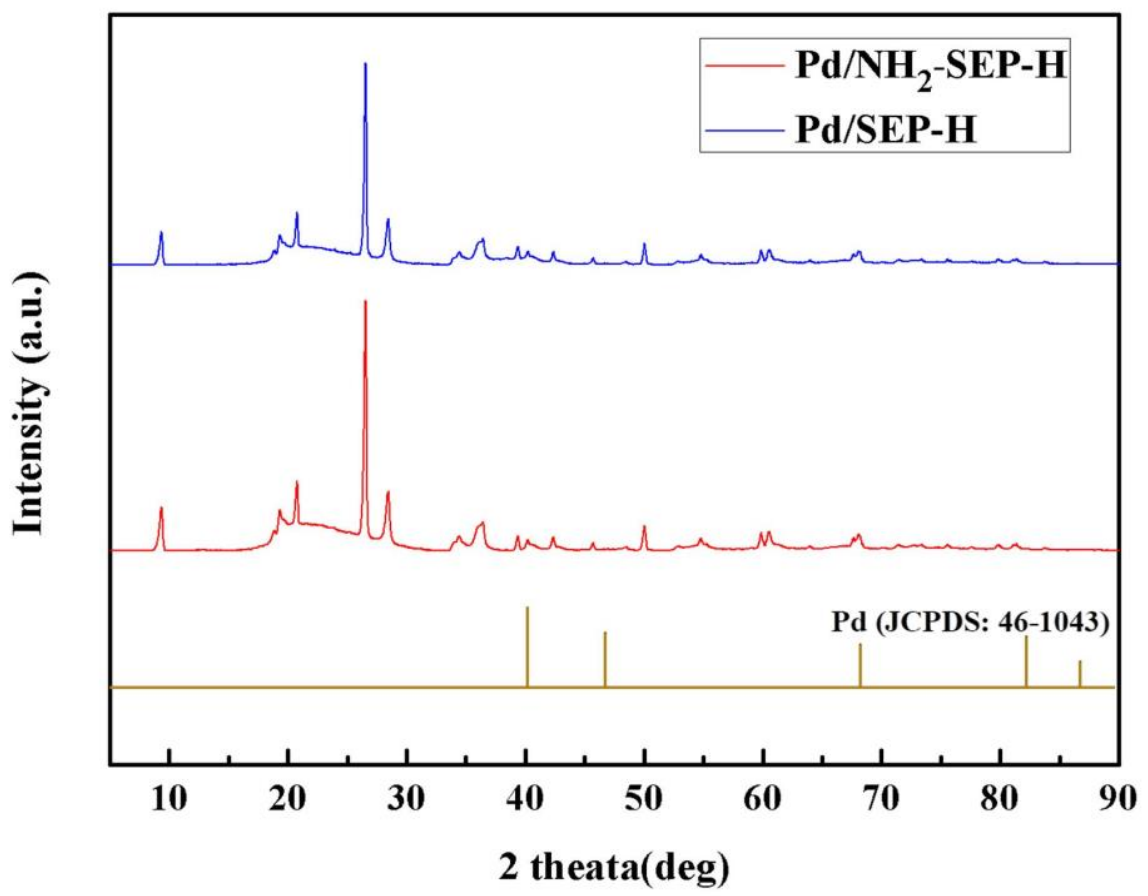

Figure S3b. XRD spectra of Pd/NH $2-\mathrm{SEP}-\mathrm{H}$ and $\mathrm{Pd} / \mathrm{SEP}-\mathrm{H}$.

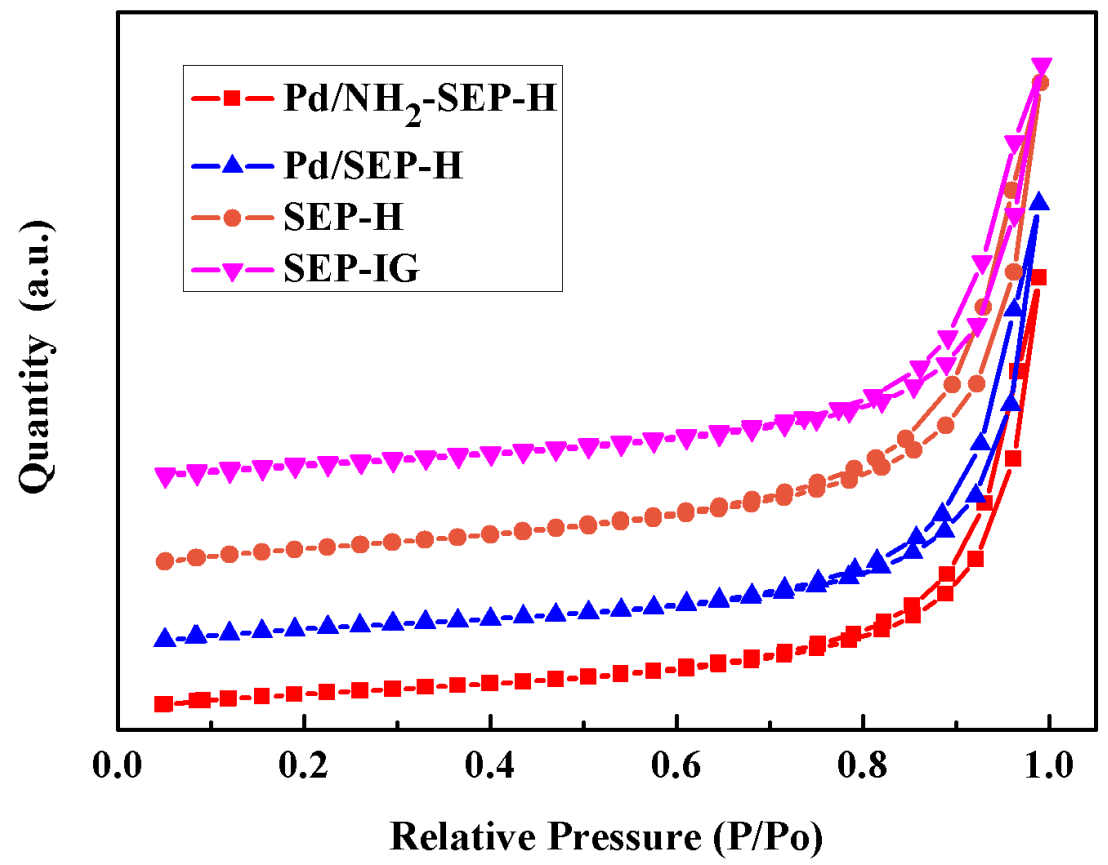

Figure S4. $\mathrm{N}_{2}$ adsorption-desorption isotherms of Pd/NH2-SEP-H, Pd/SEP-H, SEP-H and SEP-IG. 

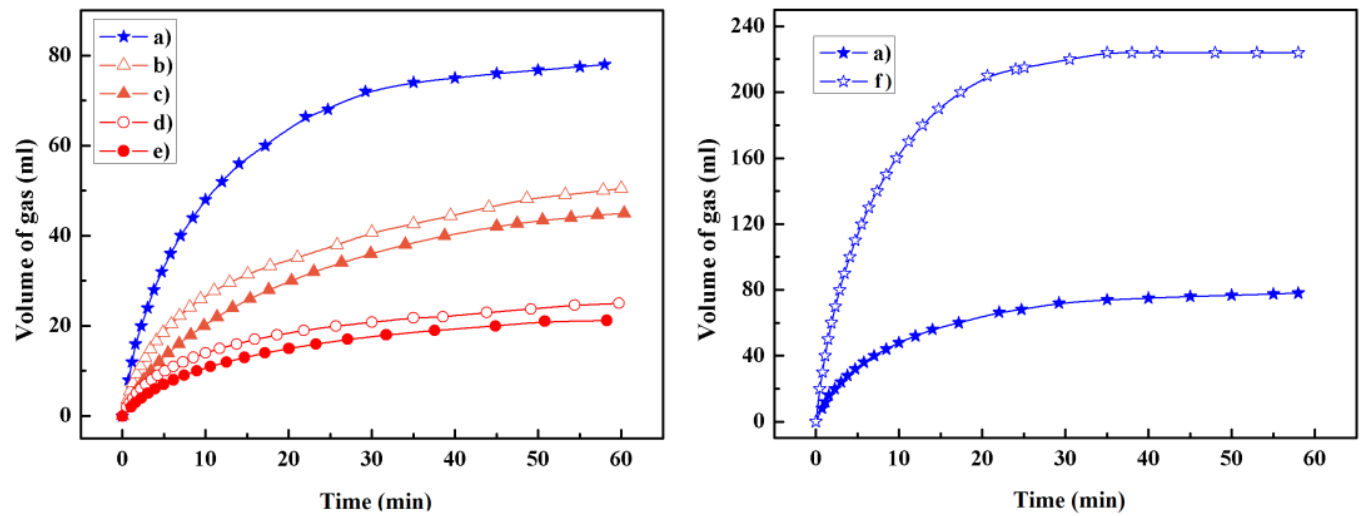

Figure S5. Comparison of catalytic reaction of FA/TEOA over the Pd based catalysts using (a). SEP-H, (b). $\mathrm{NH}_{2}-\mathrm{XC}-72-\mathrm{H},(\mathrm{c}) . \mathrm{XC}-72-\mathrm{H},(\mathrm{d}) . \mathrm{NH}_{2}-\mathrm{g}-\mathrm{C}_{3} \mathrm{~N}_{4}-\mathrm{H}$, (e) g- $\mathrm{C}_{3} \mathrm{~N}_{4}-\mathrm{H}$ and (f). $\mathrm{NH}_{2}-\mathrm{SEP}-\mathrm{H}$ as supports. Reaction conditions: $5.0 \mathrm{~mL}$ scale of initial solution (hybrid system: $5.5 \mathrm{mmol}$ FA, $0.5 \mathrm{mmol}$ TEOA), $750 \mathrm{rpm}$ of stirring speed, $303 \mathrm{~K}$ of reaction temperature.

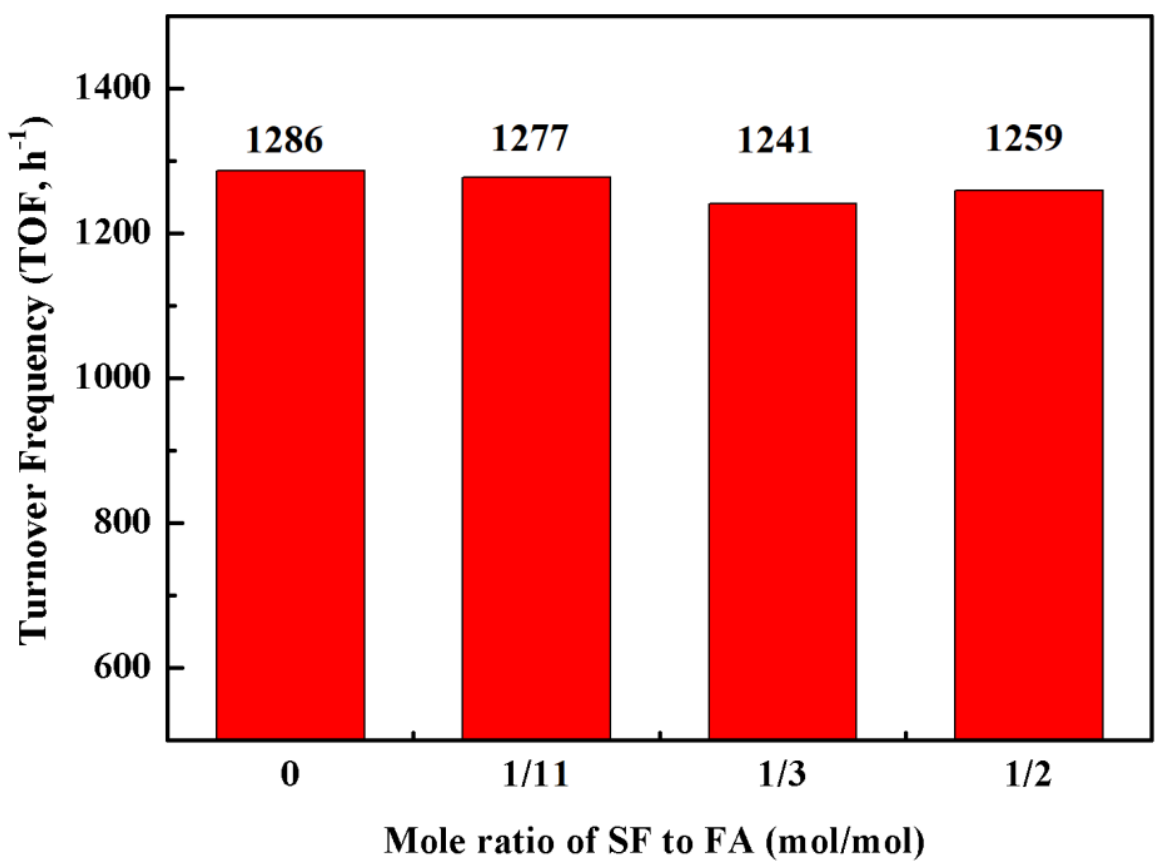

Figure S6. Comparison between systems with different SF/FA mole ratio using the $\mathrm{Pd} / \mathrm{NH}_{2}-\mathrm{SEP}-\mathrm{H}$ catalyst. Reaction conditions: $5.0 \mathrm{~mL}$ scale of initial solution (5.5 mmol FA, $0.5 \mathrm{mmol} \mathrm{SF}$ ), 750 rpm of stirring speed, $303 \mathrm{~K}$ of reaction temperature, $35 \mu \mathrm{mol} \mathrm{Pd}$. 


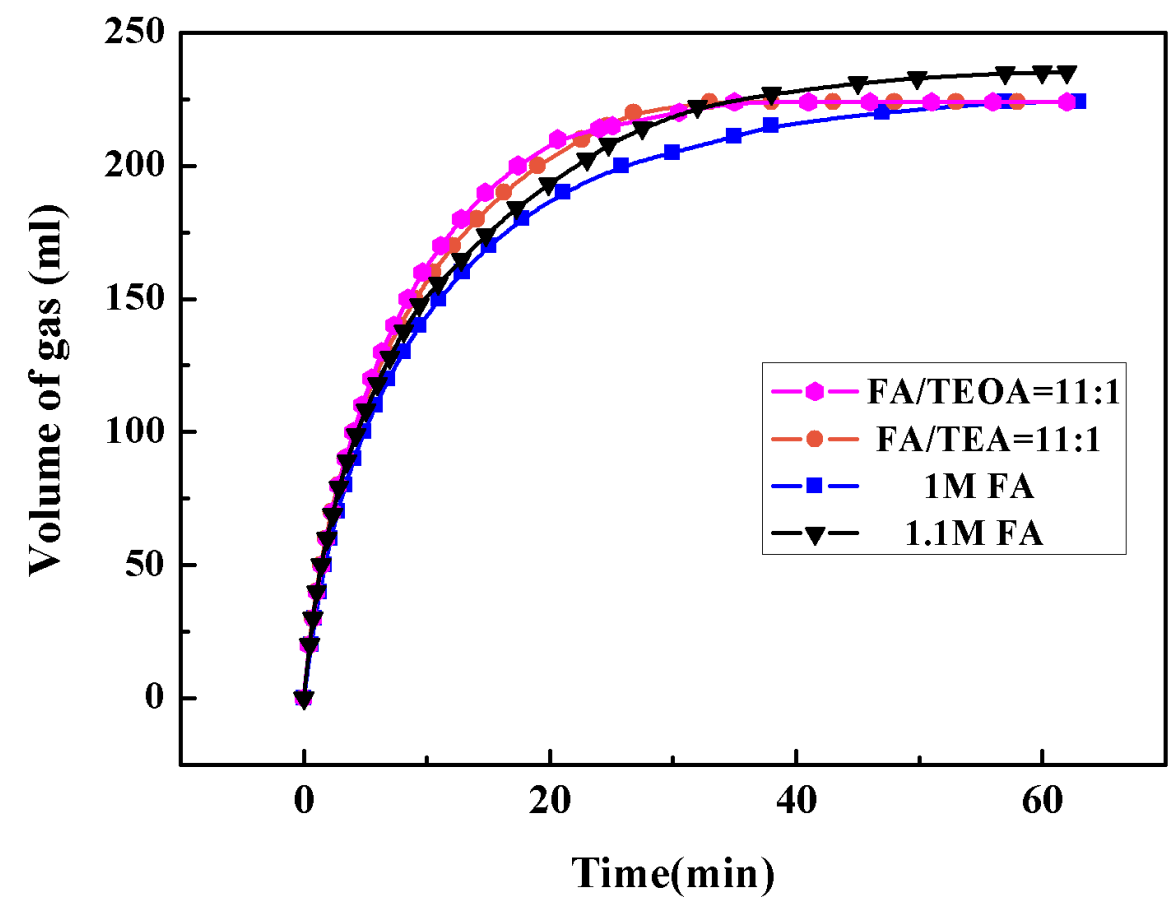

Figure S7. Comparison between TEOA, TEA and 1.1M FA system using the $\mathrm{Pd} / \mathrm{NH}_{2}-\mathrm{SEP}-\mathrm{H}$ catalyst (volume of gas vesus time). Reaction conditions: $5.0 \mathrm{~mL}$ scale of initial solution (5.5 mmol FA, $0.5 \mathrm{mmol}$ amine), $750 \mathrm{rpm}$ of stirring speed, $303 \mathrm{~K}$ of reaction temperature, $35 \mu \mathrm{mol} \mathrm{Pd}$.

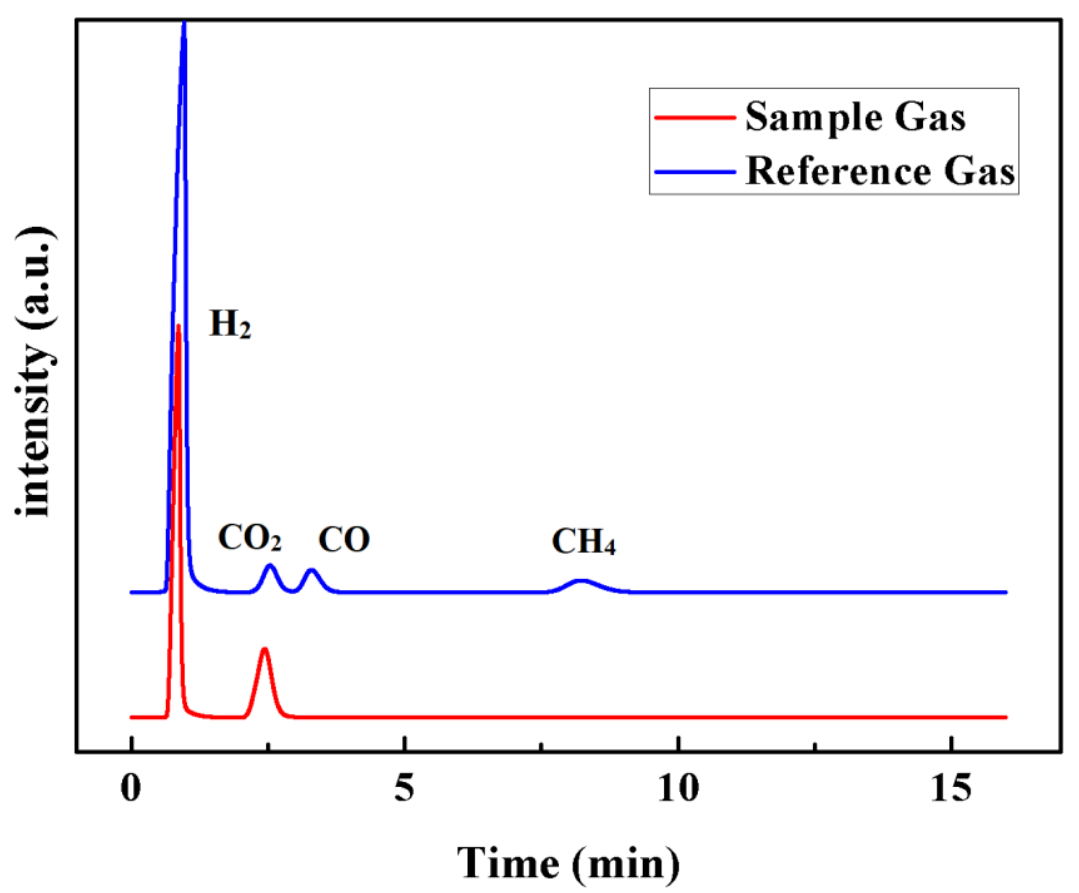

Figure S8. GC spectrum using TCD for standard reference gas and evolved sample gas from FA/TEOA aqueous solution ( $35 \mu \mathrm{mol} \mathrm{Pd}, 5.5 \mathrm{mmol} \mathrm{FA}, 0.5 \mathrm{mmol}$ TEOA) over $\mathrm{Pd} / \mathrm{NH}_{2}-\mathrm{SEP}-\mathrm{H}$ 
catalyst at $303 \mathrm{~K}$.

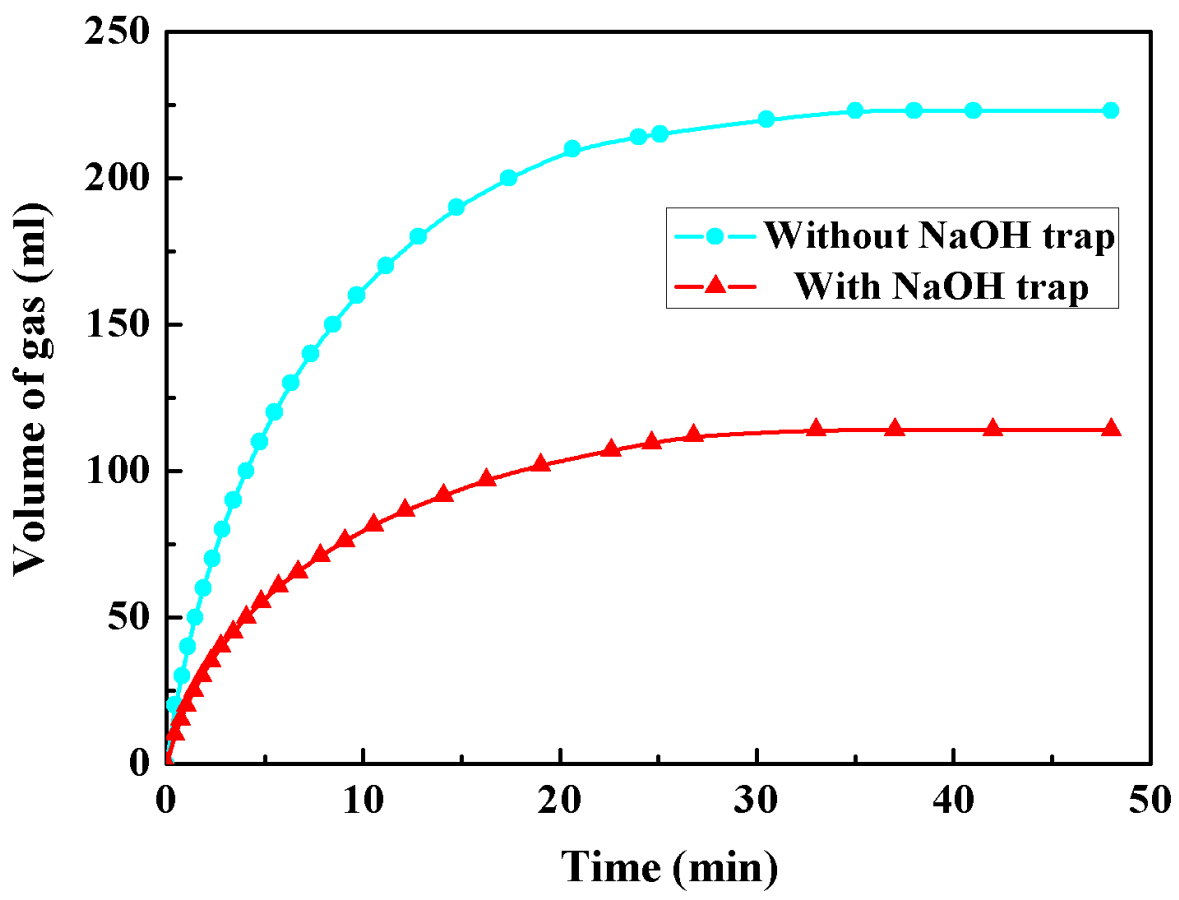

Figure S9. Gas generation by decomposition of FA/TEOA versus time over $\mathrm{Pd} / \mathrm{NH}_{2}-\mathrm{SEP}-\mathrm{H}$ catalyst at $303 \mathrm{~K}$ with and without $\mathrm{NaOH}$ trap ( $35 \mu \mathrm{mol} \mathrm{Pd}, 5.5 \mathrm{mmol} \mathrm{FA}, 0.5 \mathrm{mmol}$ TEOA)

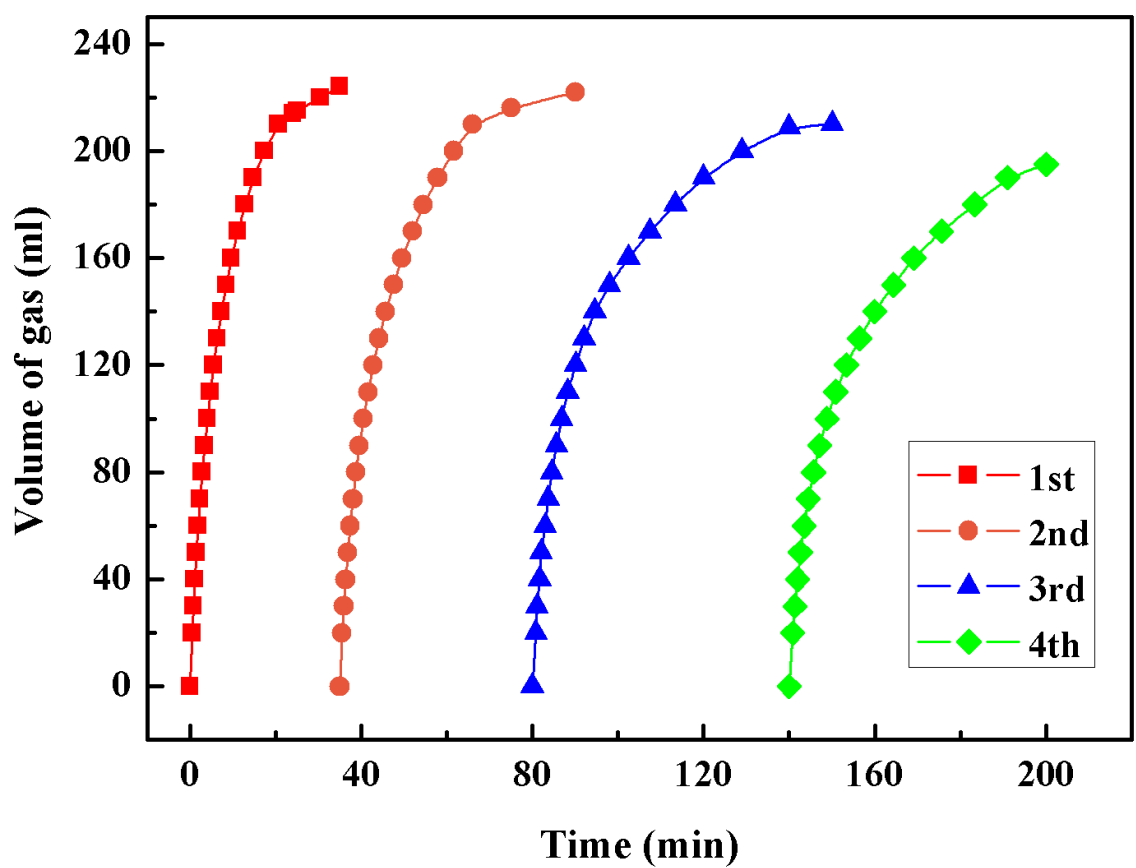

Figure S10. Catalyst stability test on the $\mathrm{Pd} / \mathrm{NH}_{2}-\mathrm{SEP}-\mathrm{H}$ catalyst in hybrid FA/TEOA dehydrogenation system 


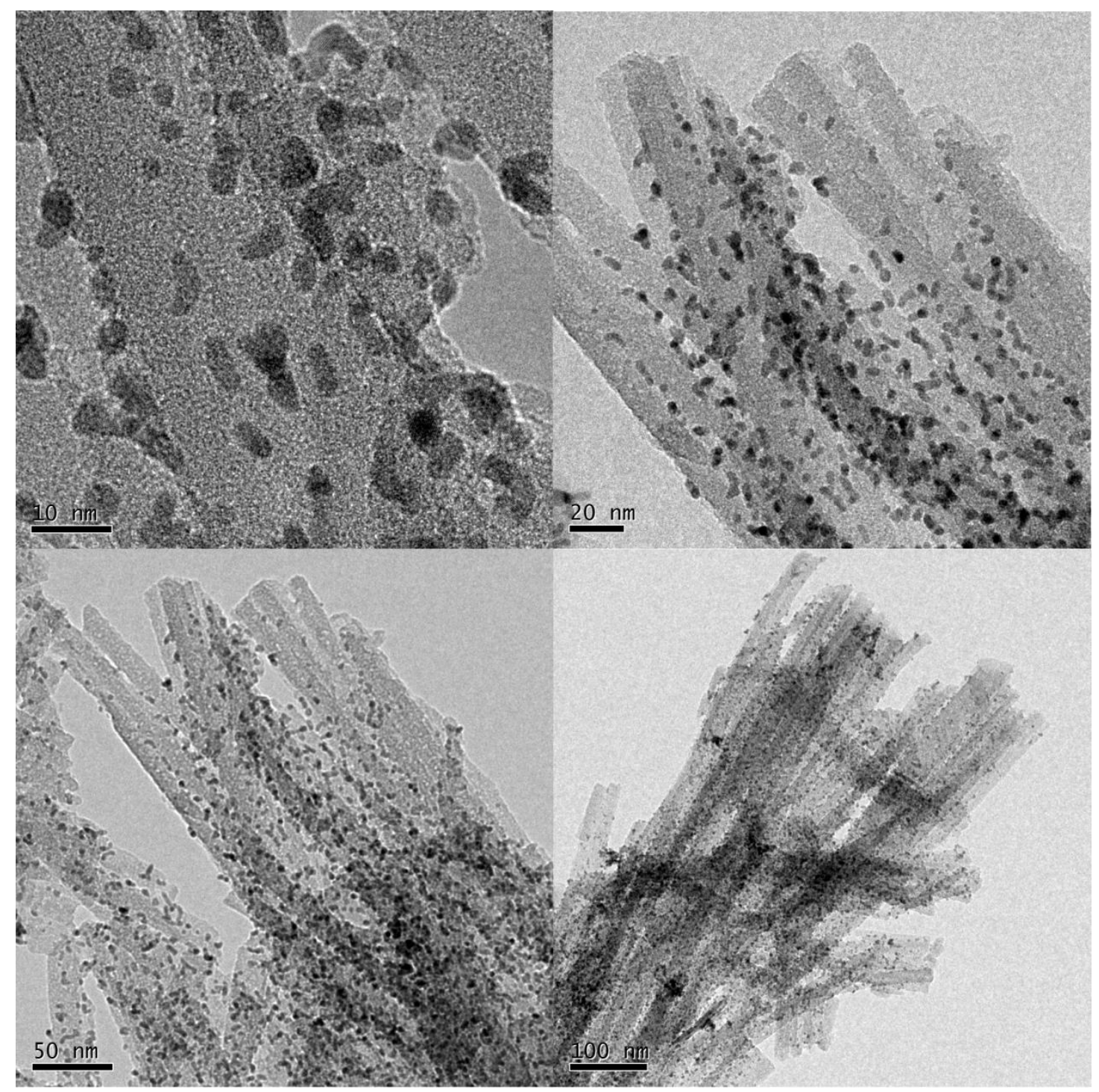

Figure S11. TEM images of 3th recycled $\mathrm{Pd} / \mathrm{NH}_{2}-\mathrm{SEP}-\mathrm{H}$ catalyst with different magnifications 


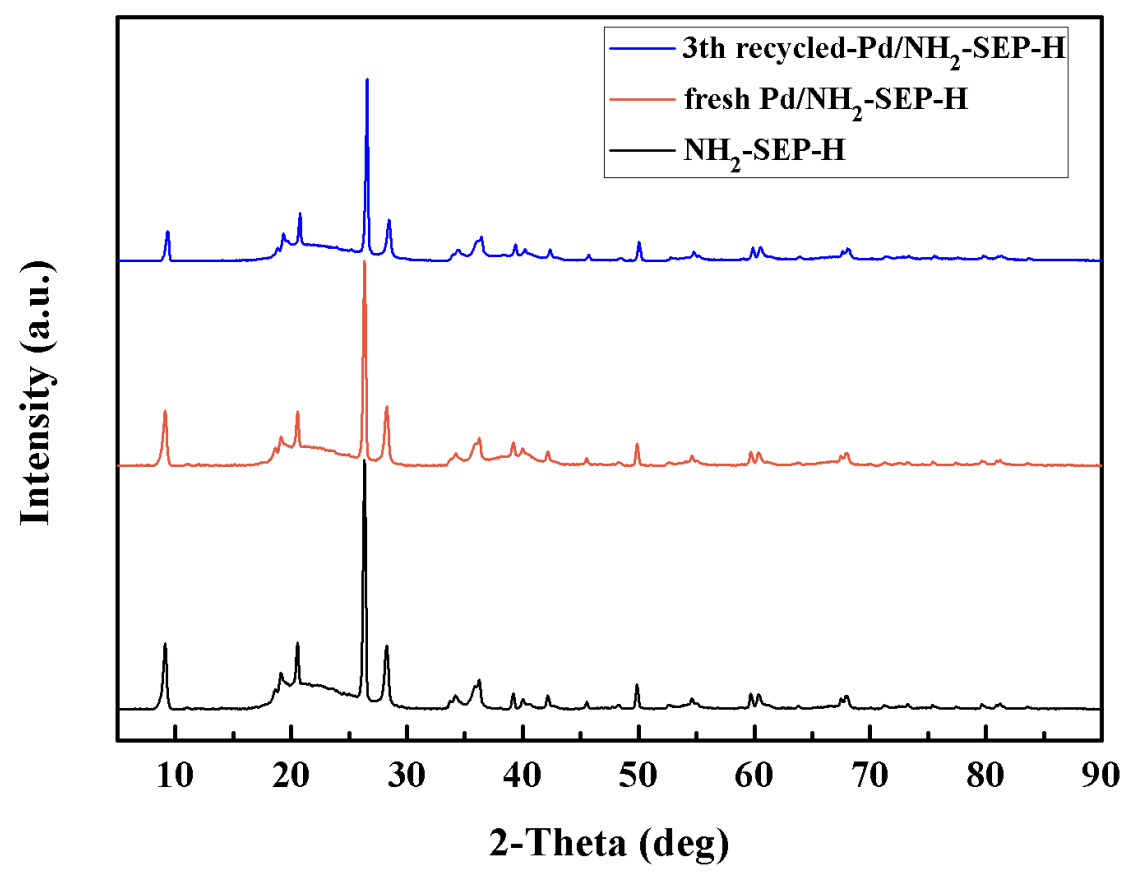

Figure S12. XRD patterns of of $\mathrm{NH}_{2}-\mathrm{SEP}-\mathrm{H}$, fresh and 3th recycled $\mathrm{Pd} / \mathrm{NH}_{2}-\mathrm{SEP}-\mathrm{H}$.

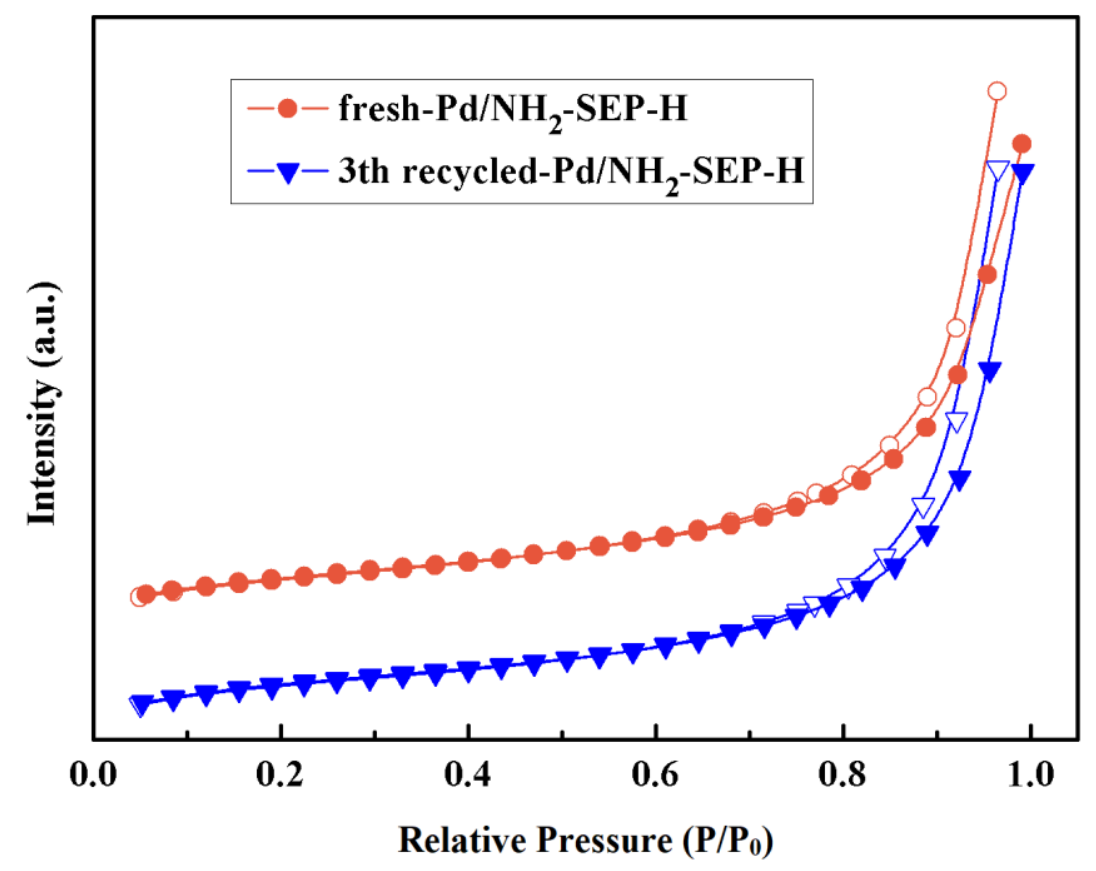

Figure S13. $\mathrm{N}_{2}$ adsorption-desorption isotherms of fresh and 3th recycled $\mathrm{Pd} / \mathrm{NH}_{2}-\mathrm{SEP}-\mathrm{H}$. 


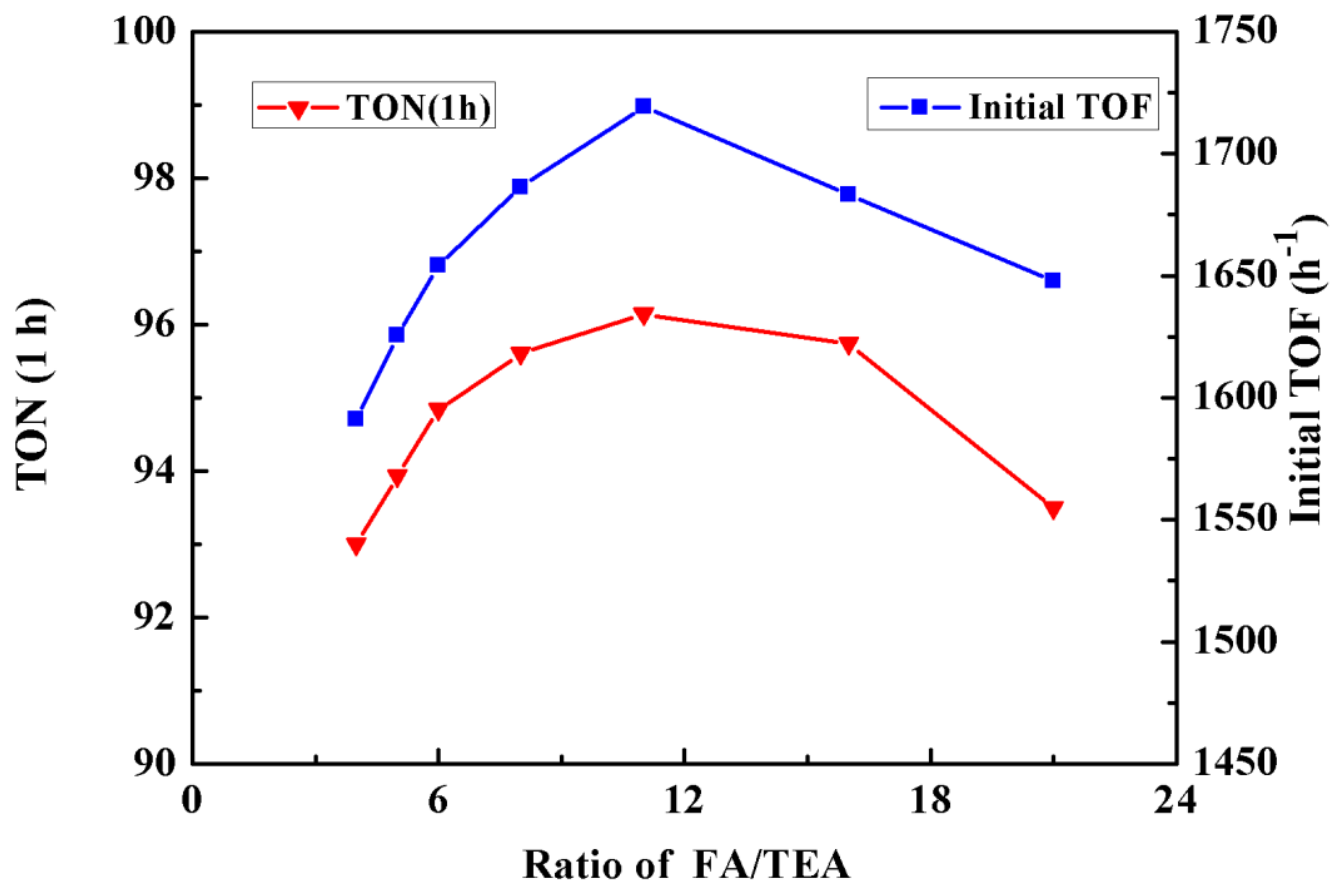

Figure S14. TON and initial TOF as the functions of the ratio of FA/TEA adduct using the $\mathrm{Pd} / \mathrm{NH}_{2}-\mathrm{SEP}-\mathrm{H}$ catalyst. Reaction conditions: $5.0 \mathrm{~mL}$ scale of initial solution, $303 \mathrm{~K}$ of reaction temperature, $750 \mathrm{rpm}$ of stirring speed, $35 \mu \mathrm{mol} \mathrm{Pd}$, reaction time $1 \mathrm{~h}$ (TON).

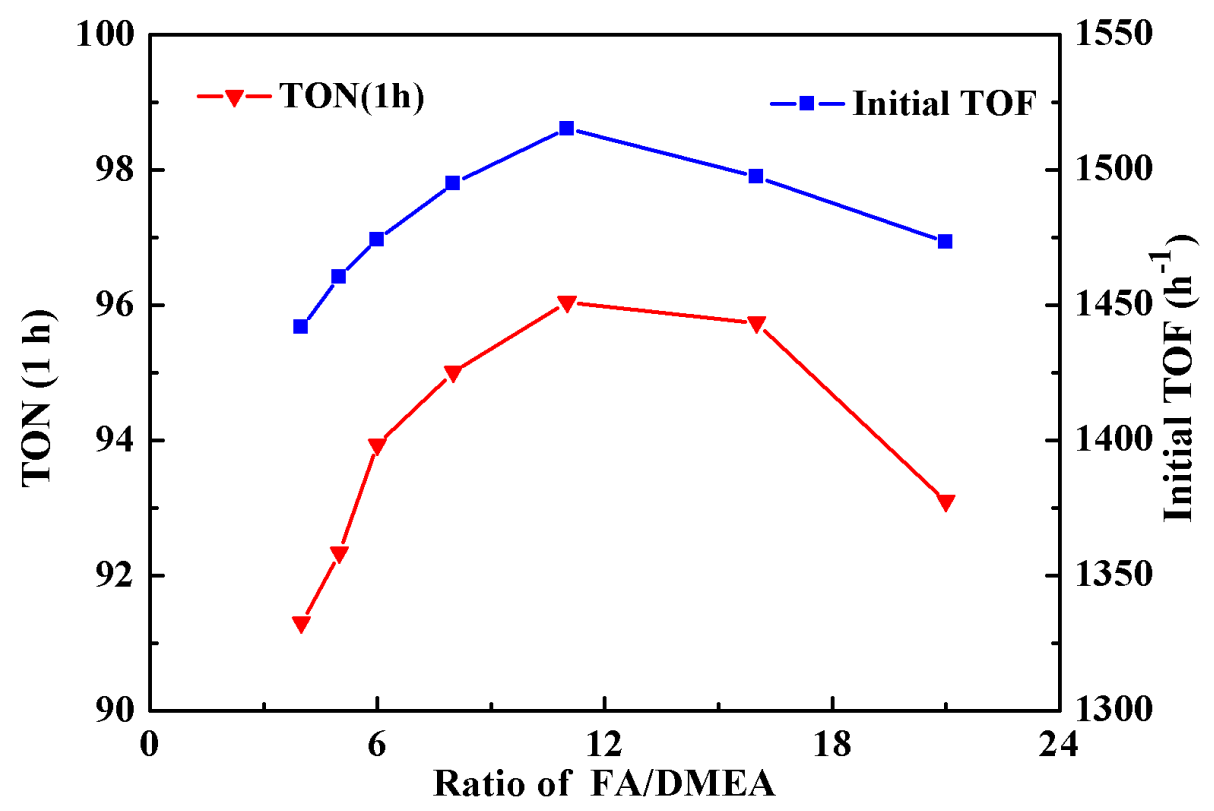

Figure S15. TON and initial TOF as the functions of the ratio of FA/DMEA adduct using the $\mathrm{Pd} / \mathrm{NH}_{2}-\mathrm{SEP}-\mathrm{H}$ catalyst. Reaction conditions: $5.0 \mathrm{~mL}$ scale of initial solution, $303 \mathrm{~K}$ of reaction temperature, $750 \mathrm{rpm}$ of stirring speed, $35 \mu \mathrm{mol} \mathrm{Pd}$, reaction time $1 \mathrm{~h}$ (TON). 


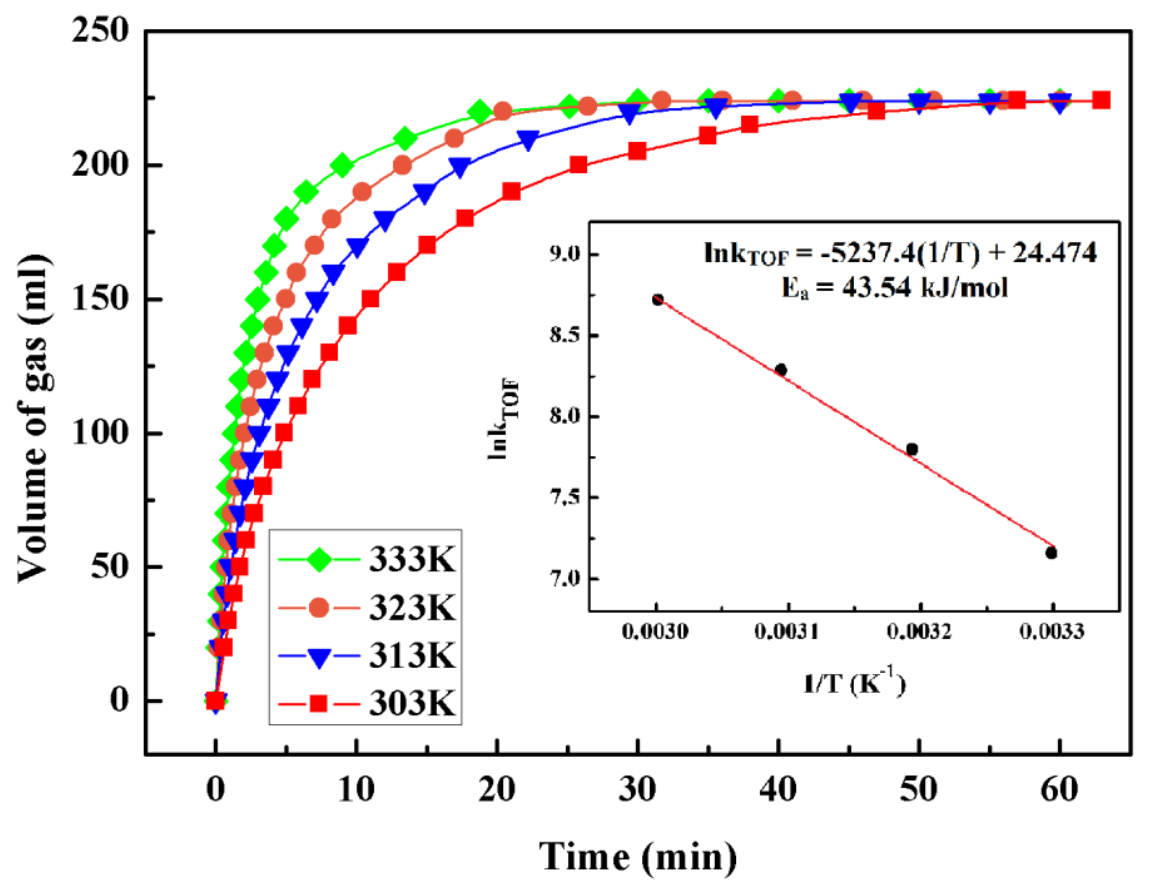

Figure S16. Effect of reaction temperature on gas evolution volume using the $\mathrm{Pd} / \mathrm{NH}_{2}-\mathrm{SEP}-\mathrm{H}$ catalyst. Reaction conditions: $5.0 \mathrm{~mL}$ scale of initial solution ( $5 \mathrm{mmol} \mathrm{FA}$ ), $750 \mathrm{rpm}$ of stirring speed, $35 \mu \mathrm{mol}$ Pd.

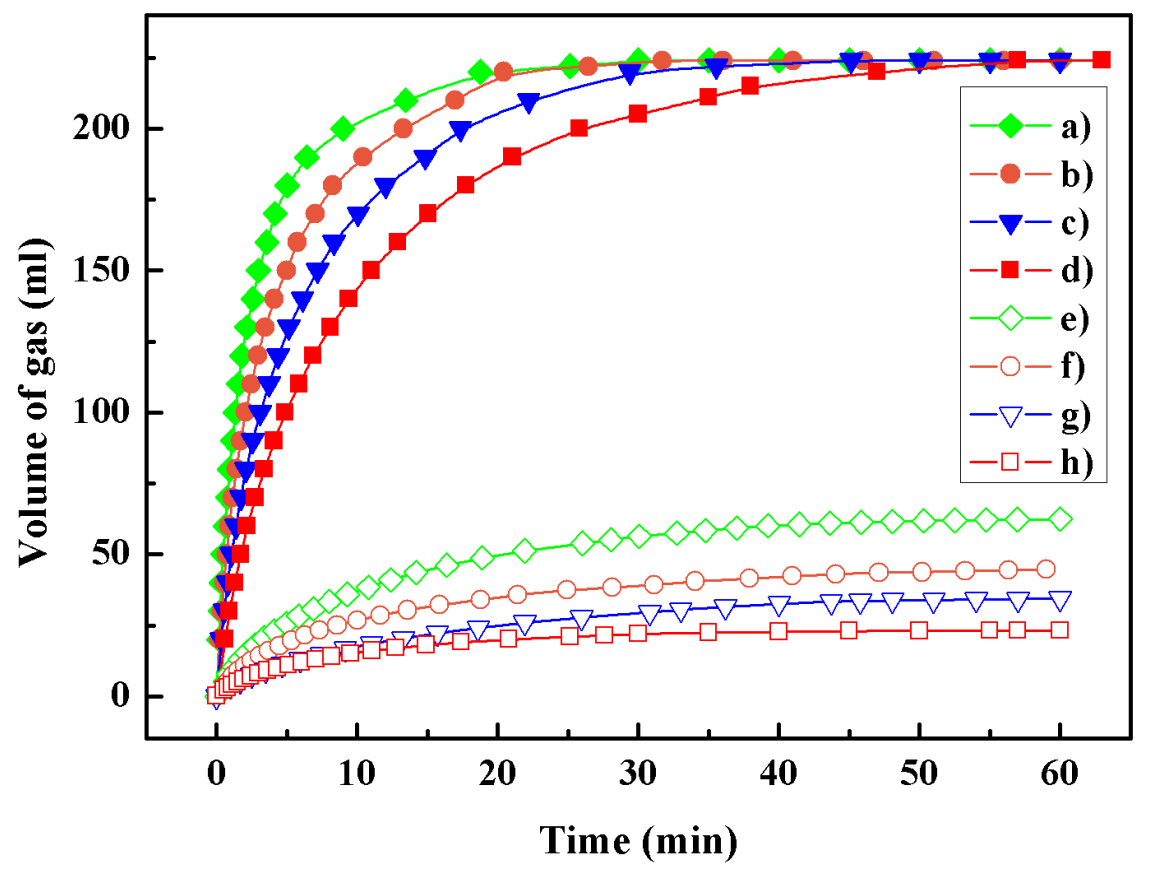

Figure S17. Total volume of gas generated from different catalyst and reaction temperature. $\mathrm{Pd} / \mathrm{NH}_{2}-\mathrm{SEP}-\mathrm{H}$ catalyst reacts at a). $303 \mathrm{~K}$, b). $313 \mathrm{~K}, \mathrm{c}$ ). $\left.323 \mathrm{~K}, \mathrm{~d}\right) .333 \mathrm{~K}$ of reaction temperature. 
Pd/SEP-H catalyst reacts at e). 303K, f). 313K, g). 323K, h). $333 \mathrm{~K}$ of reaction temperature. Reaction conditions: $5.0 \mathrm{~mL}$ scale of initial solution (5 mmol FA), $750 \mathrm{rpm}$ of stirring speed.

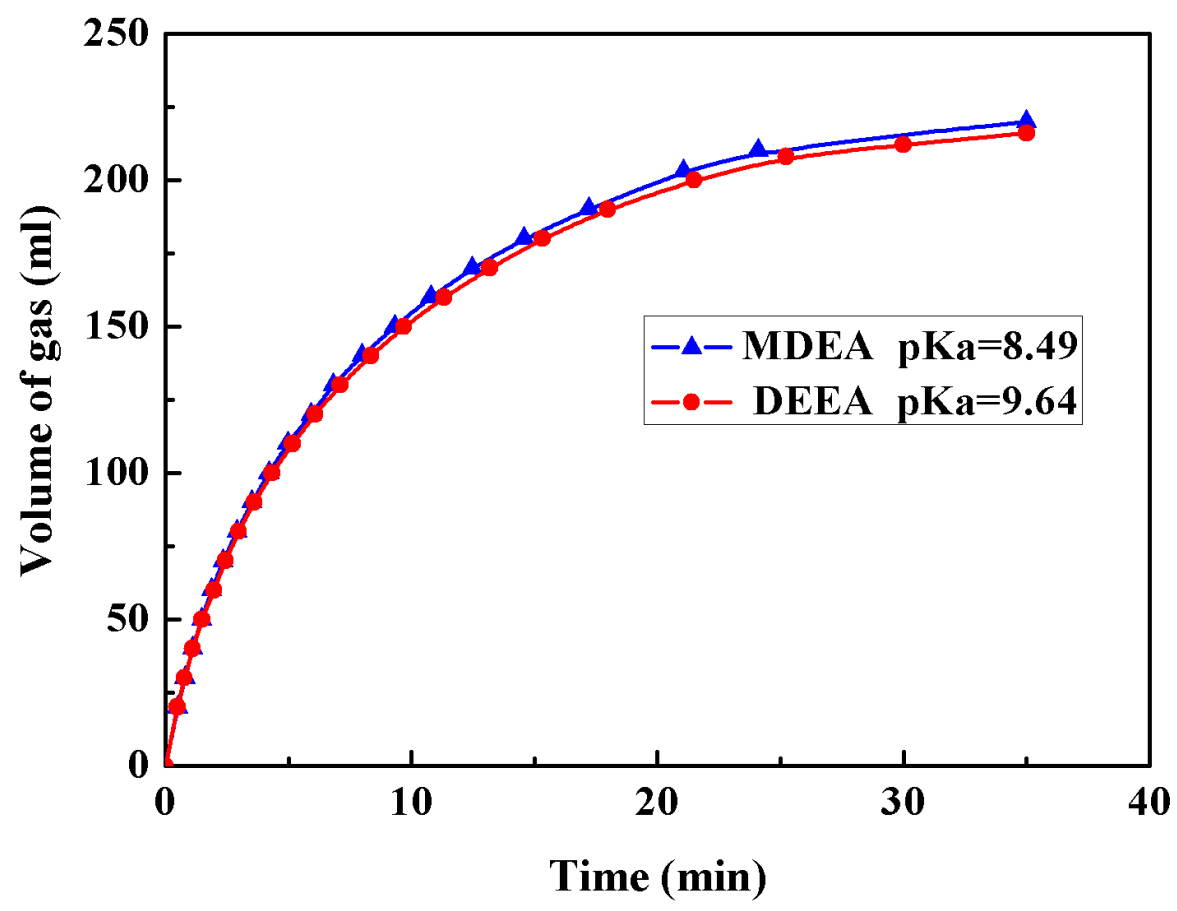

Figure S18. Comparison of catalytic reaction of FA over the $\mathrm{Pd} / \mathrm{NH}_{2}-\mathrm{SEP}-\mathrm{H}$ catalysts using MDEA and DEEA. Reaction conditions: $5.0 \mathrm{~mL}$ scale of initial solution (5.5 mmol FA, $0.5 \mathrm{mmol}$ amine), $303 \mathrm{~K}$ of reaction temperature, $750 \mathrm{rpm}$ of stirring speed, $35 \mu \mathrm{mol} \mathrm{Pd}$.

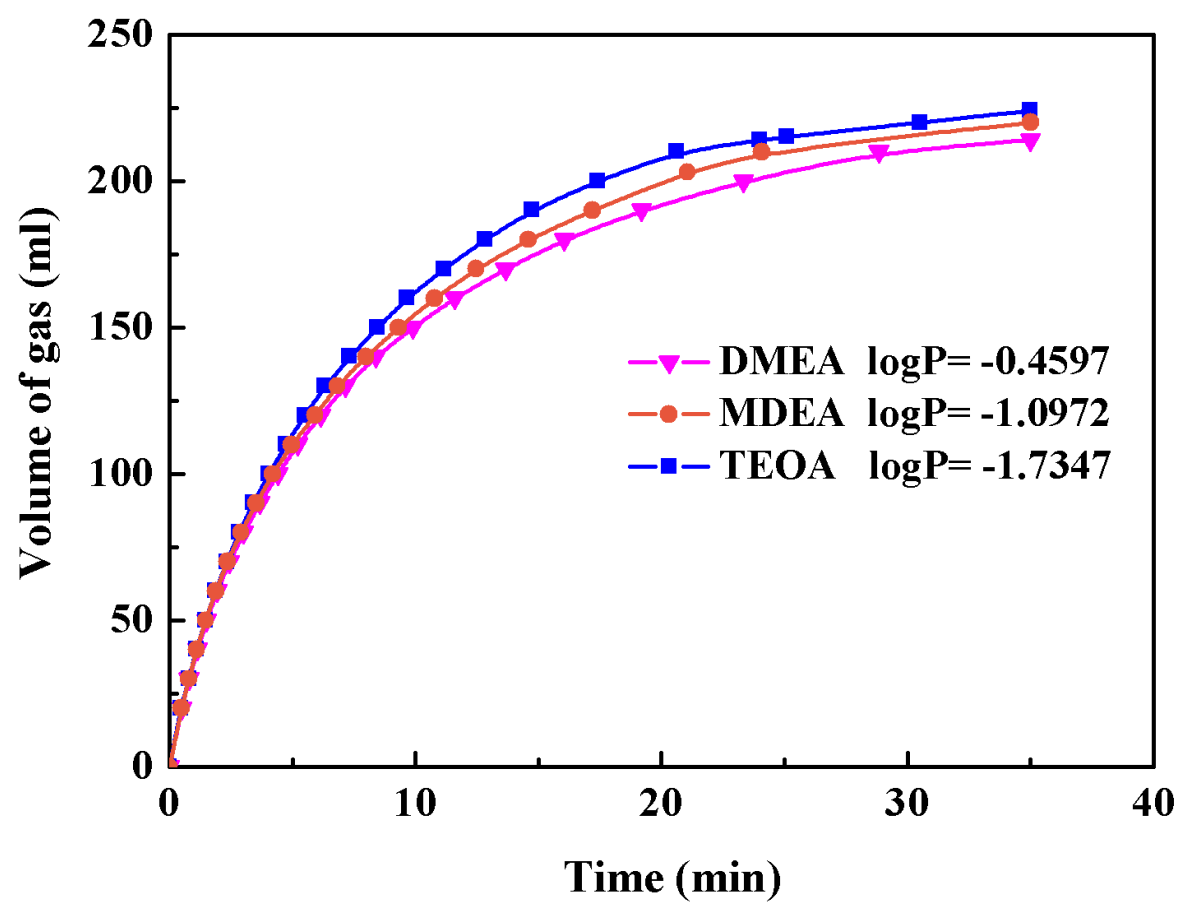


Figure S19. Comparison of catalytic reaction of FA over the Pd/ $\mathrm{NH}_{2}-\mathrm{SEP}-\mathrm{H}$ catalysts using TEOA, MDEA and DMEA. Reaction conditions: $5.0 \mathrm{~mL}$ scale of initial solution $(5.5 \mathrm{mmol} \mathrm{FA,} 0.5 \mathrm{mmol}$ amine), $303 \mathrm{~K}$ of reaction temperature, $750 \mathrm{rpm}$ of stirring speed, $35 \mu \mathrm{mol} \mathrm{Pd}$.

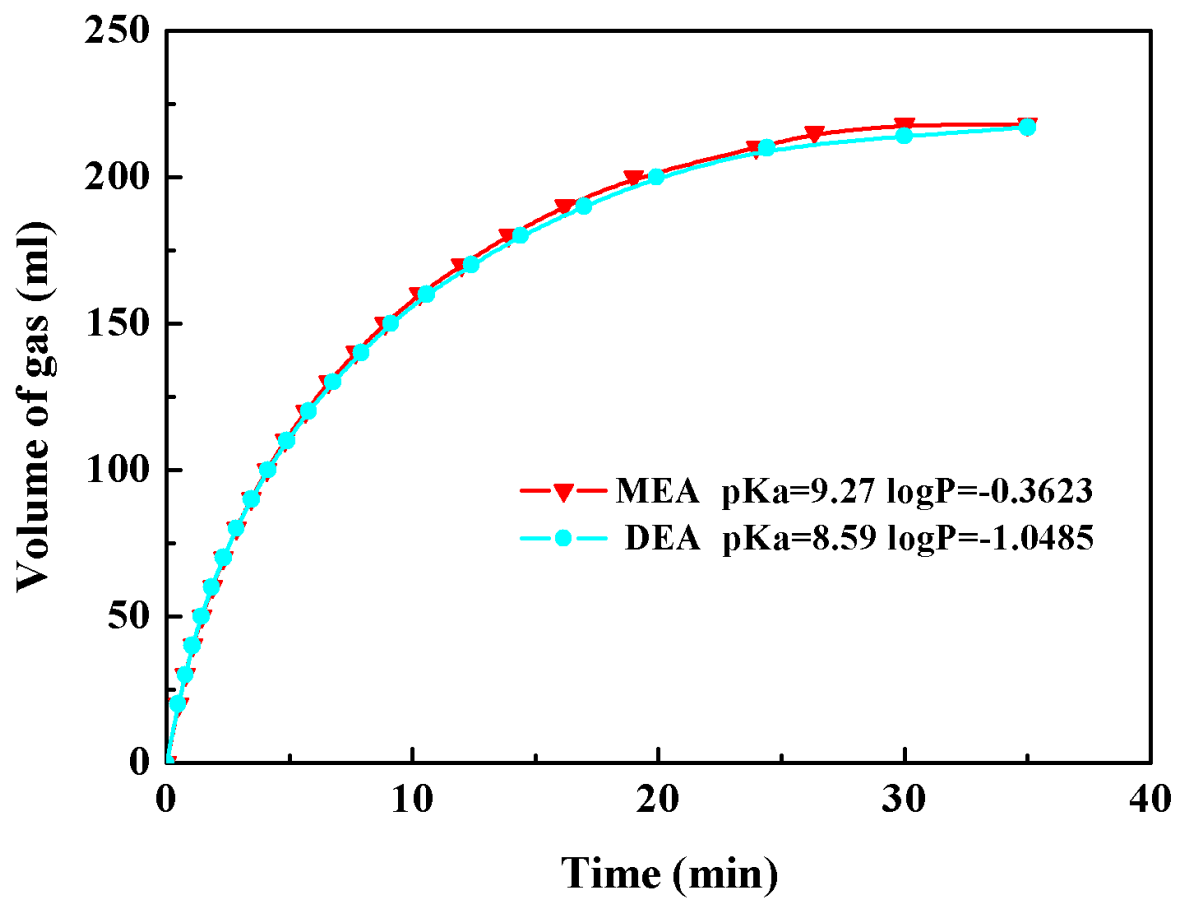

Figure S20. Comparison of catalytic reaction of FA over the $\mathrm{Pd} / \mathrm{NH}_{2}-\mathrm{SEP}-\mathrm{H}$ catalysts using MEA and DEA. Reaction conditions: $5.0 \mathrm{~mL}$ scale of initial solution (5.5 mmol FA, $0.5 \mathrm{mmol}$ amine), $303 \mathrm{~K}$ of reaction temperature, $750 \mathrm{rpm}$ of stirring speed, $35 \mu \mathrm{mol} \mathrm{Pd}$.

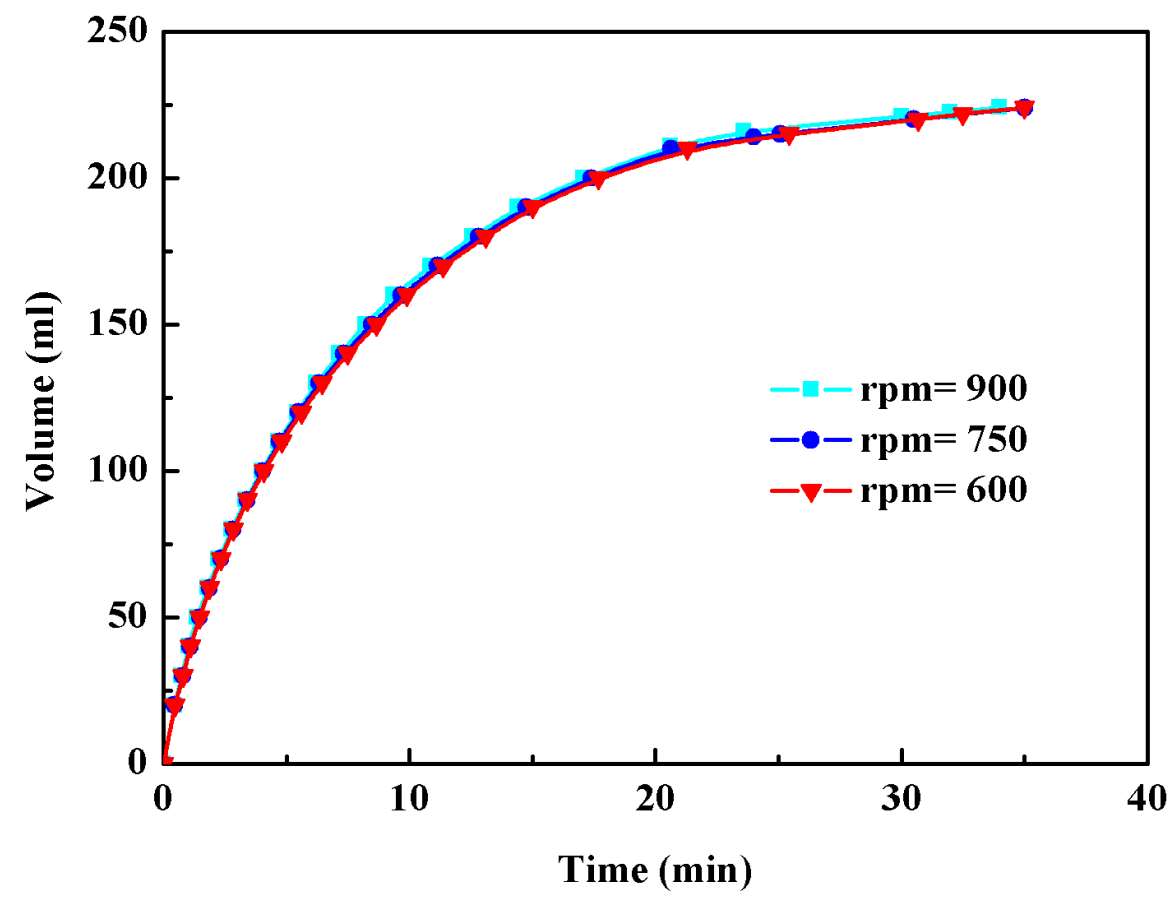


Figure S21. Effect of stirring speed on gas evolution volume. Reaction conditions: $5.0 \mathrm{~mL}$ scale of initial solution (5.5 mmol FA, $0.5 \mathrm{mmol}$ TEOA), $303 \mathrm{~K}$ of reaction temperature, $35 \mu \mathrm{mol} \mathrm{Pd}$.

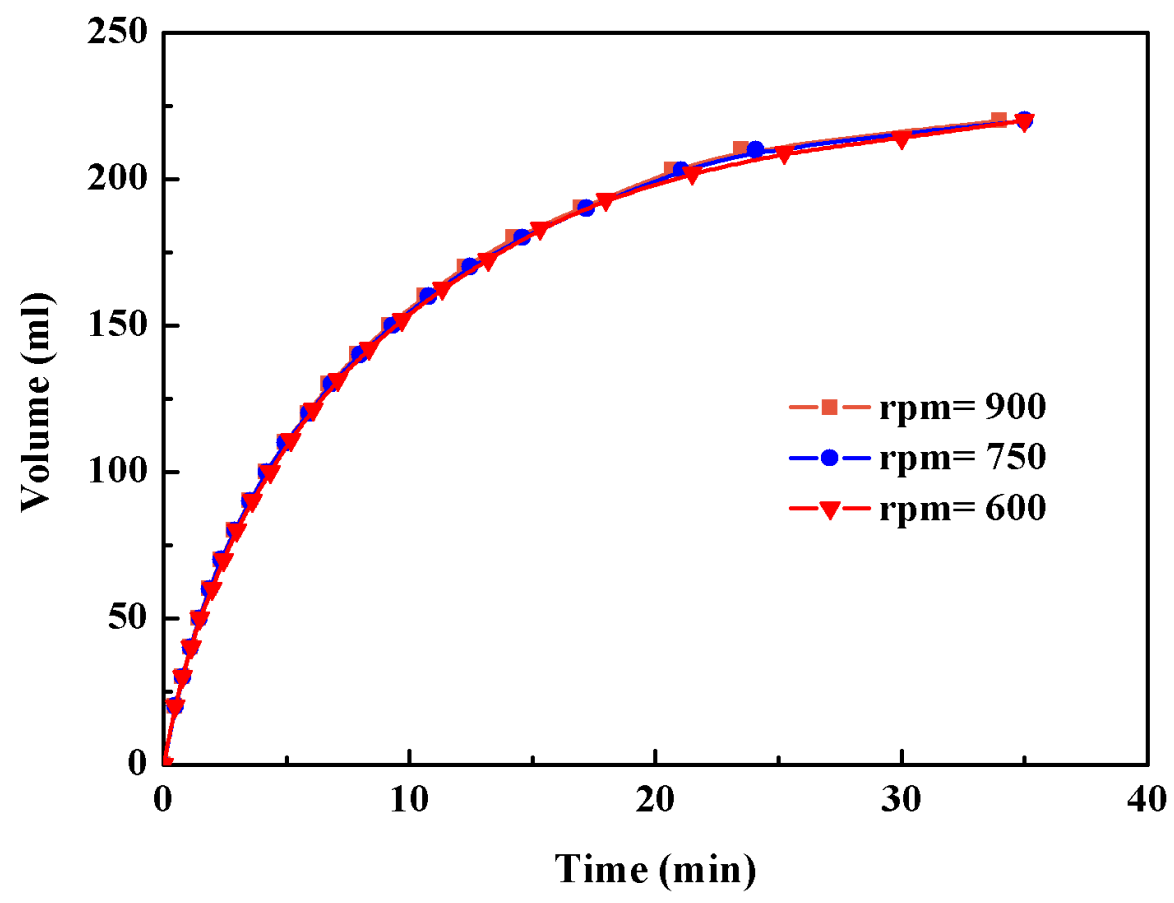

Figure S22. Effect of stirring speed on gas evolution volume. Reaction conditions: $5.0 \mathrm{~mL}$ scale of initial solution (5.5 mmol FA, $0.5 \mathrm{mmol}$ MDEA), 303K of reaction temperature, $35 \mu \mathrm{mol} \mathrm{Pd}$. 